\title{
Muerte en los Andes: sociedad colonial y mortalidad en las haciendas andinas (Ecuador, 1743-1857)*
}

\author{
María José Vilalta*
}

La vida cotidiana en las haciendas coloniales implicó la introducción de una forma de administración de poblaciones impuesta sobre la sociedad indígena y regulada por las Leyes de Indias. En la zona norte de los Andes, el concertaje de indios y la abundancia de trabajos en la agricultura y en los obrajes fueron factores de atracción que generaron la tendencia a un crecimiento poblacional de larga duración. Más allá del debate inconcluso sobre la catástrofe demográfica en las Indias, este estudio investiga los perfiles y la incidencia de la mortalidad ordinaria y catastrófica como factor de regulación del crecimiento de la población en una parroquia de hacienda en la etapa final de los tiempos coloniales. La investigación se fundamenta en el vaciado nominal completo de libros de entierros incluidos en series de registros parroquiales. Los datos de la mortalidad analizados se extienden desde pocos años después de la fundación de la parroquia hasta 1857, momento de la supresión del tributo indígena, que se considera como año final de observación a pesar de la continuidad del registro. Las evidencias muestran una realidad marcada por una mortalidad de ciclo demográfico antiguo, dominada por el peso de las condiciones de vida adversas y el trabajo en la hacienda. Además, los datos permiten adentrarse en el universo de las rígidas clasificaciones sociales del mundo colonial.

Palabras clave: Mortalidad. Población indígena. Régimen de hacienda. América colonial. Andes del Ecuador.

\footnotetext{
* Este trabajo se desarrolló en el marco de un proyecto de investigación financiado por el Ministerio de Ciencia e Innovación (MCIN) (plan nacional 2012-2014) titulado Hegemonía, dominación y administración de poblaciones en América Latina: continuidades y cambios (CSO2011-23521).

** Departament d'Història de l'Art i Història Social, Facultat de Lletres, Universitat de Lleida, Lleida, España (vilalta@hahs. udl.cat).
} 


\section{Introducción. Problemas generales y estudio de caso}

Una muy consolidada tradición de investigación sobre las sociedades indígenas y su toma de posición y de conciencia en el largo proceso de disolución del régimen señorial de las haciendas plantea numerosas interpelaciones, y algunas de ellas solo pueden resolverse plenamente desde la perspectiva histórica. En este marco, dos objetivos resumen la magnitud de los problemas que se abordan en este artículo: primero, aportar nuevos datos sobre la tan debatida catástrofe demográfica americana, no ya desde los impactos iniciales de la conquista, sino en los procesos de cambio poblacional de larga duración en la etapa colonial (LIVI BACCI, 2005), y segundo, intentar caracterizar algunos rasgos de los ciclos vitales de las personas involucradas en la lenta trayectoria de disolución de las haciendas coloniales.

La muy lenta, difícil y desigual incorporación de la población indígena a la vida política y social en América Latina tiene mucho que ver con su larga historia como colectivo sujeto al régimen de administración de poblaciones -tal como lo definió A. Guerrero $^{1}$-, que fue impuesto, en etapas diversas, primero por gobernantes autóctonos, después por el poder colonizador metropolitano y más tarde por los regímenes republicanos creados con posterioridad al proceso emancipador. En el ámbito andino se produjo, pues, una transformación de gran calado: una suplantación por etapas de las estructuras de poder que sometían a las poblaciones subalternas (CHATURVEDI, 2000). Es decir, aniquilado el poder de los Incas, se impusieron los conquistadores de la Monarquía hispánica, quienes perpetuaron estructuras de dominación y segregación de tan larga duración que su impronta subsistió, por contradictorio que pueda parecer, en el proceso de consolidación de los nuevos regímenes democráticos y representativos del Estado nacional republicano (GUERRERO, 2010, p. 17-18). Los administrados, los vencidos (WACHTEL, 1976), fueron en cada caso los mismos: los quichuas, organizados en numerosos "pueblos" en el "megadiverso y pluricultural” espacio andino (RAMÓN VALAREZO; TORRES DÁVILA, 2004, p. 15-23).

\footnotetext{
$\overline{1}$ La administración de poblaciones es "el manejo, por los ciudadanos particulares y bajo regímenes republicanos, de grupos demográficos (sobre todo en el siglo xix) que por una razón u otra de la historia no son considerados aptos para el trato cotidiano en igualdad, rasgo inherente a la condición ciudadana [...] aludo a grupos sociales que son clasificados de incivilizados o aún no suficientemente civilizados, sean cuales fueren los argumentos que se den [...] Esta problemática se inserta en el marco de una amplia discusión que trata sobre las diferentes formas que puede asumir la ciudadanía en cada entorno histórico preciso" (GUERRERO, 2010, p. 161). Se trata de un concepto pensado para la gestión republicana, pero como aquí se propone y se verá más adelante, puede hacerse extensivo al tiempo de la colonia.
} 
No queda duda ya de que, en la larga duración secular, el impacto de la conquista menguó el número de los antiguos habitantes de la zona andina (NEWSON, 1995, p. 203-225). Las trayectorias vitales de estos protagonistas de la historia inducen a pensar en procesos de adaptación y resistencia combinados para garantizar la supervivencia de cada una de las comunidades y, por ende, de sus especificidades (LYONS, 2006; BRETÓN, 2012, p. 69-78). Este conjunto complejo de trayectorias vitales fue estudiado ampliamente desde ámbitos muy diversos, desde los que se puede profundizar y aportar datos de gran relevancia en un terreno todavía poco desbrozado: las pautas de vida cotidiana de los indígenas a través de varios siglos y a partir de sus indicadores vitales y familiares primarios.

\section{En la Sierra ecuatoriana}

La parroquia rural de Toacazo (cantón Latacunga, actual provincia de Cotopaxi), en los Andes de Ecuador (véase Mapa 1), es una institución religiosa local fundada en los tiempos de la colonización española tardía en el extremo septentrional del Tawantinsuyo incásico. Situada en la falda oriental de los volcanes llinizas, el lugar ya se encontraba habitado cuando los españoles iniciaron la conquista -incluso puede que fuera un asentamiento pre-incaico. Después que Gonzalo Pizarro asumiera el nombramiento como gobernador de Quito, en 1539, pasó a formar parte del Corregimiento de Tacunga (Latacunga). En 1614 empezaron a aparecer propuestas para crear en ese emplazamiento una reducción de indios. Los motivos radicaban en su capacidad para alojar a más de mil residentes, en la mayor moderación del clima respecto a otros posibles asentamientos próximos, en la abundancia de tierras llanas y otros recursos, en la proximidad a otras poblaciones importantes (Isinliví y Latacunga) y en la facilidad que ofrecía para favorecer las comunicaciones terrestres entre pisos ecológicos muy distintos, tanto de personas de un lado a otro de la imponente cordillera andina como de los ganados hacia los pastos de las tierras de páramo (SALOMON, 1980). En este estado de cosas, muchos de los habitantes de pueblos vecinos empezaron a trasladarse a merced de las necesidades de mano de obra y de control tributario, en un proceso de cambio económico profundo impulsado por los conquistadores. Así se fundó, en 1654, el pueblo de Toacazo (QUISHPE BOLAÑOS, 1999, p. 30).

La historia de los habitantes tributarios de esta parroquia estuvo completamente ligada al régimen de hacienda desde los tiempos de la colonia hasta bien entrado el siglo xx, con los procesos de reforma agraria de 1964 y 1973. Los grandes páramos de tierras altas que circundaban el núcleo habitado acabaron siendo propiedad de unos pocos terratenientes que ejercían de forma inmutable los mecanismos de dominación habituales en el mundo colonial (KAY, 1974), y en especial el combate por los comunes, parafraseando a Marc Bloch. En este entorno, la primigenia gran hacienda jesuítica de Cotopilaló se fue fragmentando, en su largo devenir, en haciendas y estancias de variadas dimensiones como El Pongo - una gran heredad que se extendía hasta los glaciares de los volcanes Ilinizas-, Razuyacu, Yanahurco, La Moya, Quillusillín o Chizaló (BRETóN, 2012, p. 135). 
En su conjunto, se trataba de dominios de rentabilidad agrícola escasa (cereal y patatas), organizados en relaciones económicas y sociales fundadas en la microverticalidad ${ }^{2}$, y cuya importancia residía en el rol simbólico y la concentración de poder que acumularon sus titulares, gestores de la parroquia católica fundada en 1720, y de las diversas haciendas a ella vinculadas, primero por parte de los jesuitas - hasta su expulsión en 1767, cuando fueron declaradas de dominio público-, luego por otros hacendados de la sociedad colonial y más tarde republicana, sin solución de continuidad.

De todos modos, la hacienda no fue la única posibilidad ocupacional. Toda la zona fue un emplazamiento de importantes obrajes de hacienda y de comunidad dedicados a las manufacturas textiles - principalmente de lana de las ovejas criadas en los páramos y de algodón de la costa subtropical en menor medida- que concentraron importantes cantidades de empleados en tareas artesanales: según datos de 1680, eran 384 obreros en Latacunga, 300 en Sigchos (a mitades entre la encomienda de Collanas y la de Sigchos), y 150 en Mulaló (BRINES TYRER, 1988, p. 101). Los obrajes de esta zona demuestran la complejidad de las formas de producción en el mundo colonial, en el que convivían el dominio útil, que pertenecía a la comunidad indígena -aunque muy raramente se organizaran en formas cooperativas de trabajo y distribución-, el abastecimiento de maquinaria y materias primas efectuado por los encomenderos y el control de la mano de obra cedida por los caciques locales (NEWSON, 1995, p. 207). Los beneficios de la producción formaban parte del tributo debido al encomendero local de turno o a remotos propietarios metropolitanos, acaparadores ambos del dominio eminente (SLICHER VAN BATH, 2010, p. 227).

La coexistencia de dos formas de trabajo tan diversas pero interdependientes tiene una importancia crucial para explicar los vaivenes demográficos, ya que en los momentos de auge ejercieron un poderoso influjo de atracción de mano de obra que se acababa dispersando entre tareas campesinas y artesanales. El golpe económico que supuso la decadencia y el cierre de los obrajes a comienzos del siglo XVIII, como evidencia final del fracaso de la política de fomento de las manufacturas de la Monarquía hispánica en las colonias, condujo a un trasvase demográfico temporal hacia la oferta de trabajo en las haciendas, lo que además de evitar procesos de despoblación regional, permitió el refuerzo de las estructuras de sujeción del campesinado tributario.

\footnotetext{
2 La microverticalidad andina se estructura en tres grandes zonas en función de las diferentes alturas que impone el medio. Primero la parte baja, "donde se ubicaba la casa de hacienda, formada por terrenos más o menos planos, o en pendiente suave, en el fondo del valle (o de un nicho ecológico en la cordillera) al borde de algún torrente, muchas veces siguiendo su cauce". Esta parte "constituía la sección más fértil y productiva de la tierra de la hacienda y era aprovechada con procedimientos de cultivo más intensivos". Segundo la parte alta, que estaba conformada por las tierras "situadas en los declives de la cordillera, pisos intermedios que subían hasta el páramo. Según su altitud estaban consagradas al cultivo de cereales y tubérculos. El cultivo de este piso representa una serie de dificultades ligadas en particular a la erosión, a la imposibilidad de laboreo no manual, el tiempo prolongado de ciclo vegetal, los riesgos de heladas y la calidad inferior de los suelos. En algunas haciendas donde este piso alcanza una altitud superior a los $3.200 \mathrm{~m}$, no obstante, los terrenos en pendiente son preferidos para los cultivos pues su topografía los defiende contra los riesgos de heladas fuertes, contrariamente a los terrenos más planos al mismo nivel". Y tercero el páramo, que "se encuentra más allá del último piso de cultivo, zona húmeda y fría, cubierta de pastos naturales de poca calidad [...] se destinaba al pastoreo extensivo de ganado ovino y vacuno", constituyendo de hecho "una forma de tierra comunal e indivisa" explotada "por la comunidad de huasipungo y el terrateniente” (GUERRERO, apud BRETÓN, 2012, p. 49).
} 
En este marco de colonización tardía, el hallazgo inusual de los registros parroquiales completos de la parroquia central de diversas haciendas permite una reconstrucción exhaustiva de las pautas de vida, movilidad y muerte de sus habitantes -indios en abrumadora mayoría, mestizos y blancos en menor medida, y mulatos y negros en número por completo irrelevante- entre las fechas extremas del primer registro de mortalidad conservado (julio de 1743) hasta concluir en el año simbólico de 1857. La fecha de cierre del análisis es la del año en que se decreta la abolición del tributo de indios, acción que representa el final del régimen que regulaba las normas de segregación étnica y administración de poblaciones propia de los tiempos coloniales, que en teoría resultaba contradictorio con los nuevos principios de igualdad que habían de guiar la política social hacia los indígenas establecida por los nuevos regímenes republicanos posteriores a la Independencia.

El estudio de la población y su compleja estratificación por segregación étnica en la América colonial implica adentrarse en los mundos separados creados por una legislación que articulaba la República de Indios, y cuyos rasgos definidores fundamentales se centraban en la imposición de obligaciones tributarias y laborales para sus integrantes, considerados como súbditos de la Monarquía hispánica. Estas leyes construyeron a perpetuidad la definición de la condición del indígena como miembro de un grupo humano integrado, pero sujeto al sometimiento y la explotación (POLONI-SIMARD, 2006, p. 56). Y estas consideraciones previas, sobradamente conocidas, introducen los grandes problemas a tratar en el espacio parroquial de Toacazo.

Entre 1743 y 1857 se está de lleno en el período tributario. La mayor parte de la población local pertenecía a esta condición, de manera tal que la categoría de "indio tributario" (de hacienda, pueblo, parcialidad o de la Real Corona) ocupaba un volumen de población abrumador. Tal evidencia permite plantear la principal controversia demográfica de la zona, ya que aquí la población india no decreció, siguiendo la tendencia general en América, sino que aumentó, lo que permitió disponer de una mano de obra tributaria muy abundante que se canalizó hacia los sectores artesanal, agrícola y ganadero. El incremento de la población indígena revalorizó una tierra que solo interesaba a los colonizadores si disponían de mano de obra para labrarla. Así, el laboreo en las haciendas se organizó mediante el trabajo obligatorio de los tributarios, y estas transformaciones modificaron sustancialmente la vida cotidiana de las comunidades indígenas (LUCENA SALMORAL, 2007, p. 489)

Este "aumento constante" puede verificarse en las diversas fuentes que proporcionan información demográfica. El punto de arranque debe tomarse en la tremenda crisis de 1690, que como es habitual en parajes volcánicos, vino acompañada de accidentes naturales (terremotos y erupciones), epidemias y movimientos en fuga de la población residente. A partir de este punto crítico se inició la recuperación, de tal manera que a mediados de la siguiente centuria se convino en la necesidad de la fundación de la parroquia. Según los datos de algunos padrones conservados, la provincia de Latacunga pasó de 49.919 habitantes en $1779-1781$ a 55.814 en 1825 , lo que supuso un incremento de un $12 \%$ (ANDRIEN, 2002, p. 39). En 1779 esta población estaba compuesta por 55 clérigos (0,11\%), 
11.543 europeos (23,1\%), 37.978 andinos (76\%), 372 miembros de castas $(0,74 \%)$ y 20 esclavos (0,05\%), quienes según lo conservado en los padrones de Latacunga de 1779 , 1780, 1782 y 1784 del Archivo Nacional de Historia de Quito sumaban un total 49.968 habitantes (ANDRIEN, 2002, p. 39). Ambas tendencias, tanto de crecimiento como de composición social, se mantuvieron estables, según lo muestran los escasos datos de balance demográfico de adultos (personas de confesión o listas de cumplimiento pascual) que ofrecen los libros parroquiales de San Antonio de Toacazo (en adelante APT) en años cruciales que coincidieron con la inestabilidad política y social que siguió a la muerte de Simón Bolívar (1783-1830) (véase Tabla 1).

TABLA 1

Personas de confesión por etnia en la parroquia de San Antonio de Toacazo 1830-1835

\begin{tabular}{lccccc}
\hline Año & Indios & $\%$ & Blancos & $\%$ & Total \\
\hline 1830 & 1.213 & 86,6 & 188 & 13,4 & 1.401 \\
1831 & 1.361 & 85,1 & 238 & 14,9 & 1.599 \\
1832 & 1.402 & 83,3 & 281 & 16,7 & 1.683 \\
1833 & 446 & 63,4 & 257 & 36,6 & 703 \\
1834 & - & - & - & - & 1.562 \\
1835 & 1.454 & 83,3 & 291 & 16,7 & 1.745 \\
\hline
\end{tabular}

Fuente: Archivo Parroquial de Toacazo (APT), Bautismos (1800-1837), Libro VI, Registro 3C51-78-83, p. 194r, 205d, 234d, 250d, $260 \mathrm{~d}$ y $272 \mathrm{~d}$.

Los datos sobre la trayectoria de la población adulta en esos pocos años parecen indicar dos posibles interpretaciones: una, la notable superioridad del contingente indígena sobre la minoría blanca de nueva implantación, y otra, la progresiva tendencia al crecimiento, a pesar de la notable disminución de 1833 -que vino precedida de dos años críticos de sobremortalidad- y la de 1834, en la que la enfermedad del cura sirvió de excusa para justificar un registro incompleto de adultos de confesión. A la vista de los guarismos disponibles se puede proponer una primera vía de análisis, a través de la mortalidad, que permita fijar preliminarmente algunos de los principales límites a los que se pudo enfrentar el manifiesto crecimiento de la población de la zona norandina.

\section{Los estragos de la mortalidad}

Diversos autores han propuesto vías para la interpretación de algunos asuntos combinados que son sustanciales para conocer las variaciones de la población desde la plenitud del régimen de hacienda, desde el siglo XVII en adelante. Estos asuntos son el impacto de las frecuentes crisis demográficas (enfermedad y catástrofes naturales), los intentos de evasión del pago del tributo indígena (fuente de movilidad de población) y la consolidación del concertaje, que garantizaba la continuidad de la mano de obra en encomiendas que luchaban por crecer a costa de tierras comunales (BRETÓN, 2012, p. 40). Solo adentrarse en la complejidad de la reconstrucción de familias permitiría obtener alguna referencia 
clara a las magnitudes de los movimientos de población, probablemente pendulares entre las fuerzas contrapuestas de la evasión y la sujeción a la tierra. Por el momento, lo que resulta factible es indagar en el significado y las implicaciones de los estragos que produjo la mortalidad.

Una primera consideración obliga a reseñar las características de los datos disponibles. El registro de mortalidad de la parroquia de Toacazo abarca el período comprendido entre julio de 1743 hasta la actualidad, aunque la fecha final de observación sea 1857, como ya se ha comentado. Los datos conservados muestran la calidad de la serie, a pesar del bajo número de inscripciones en los años que coinciden con el ciclo revolucionario de los primeros levantamientos (motín de 1765), la revolución (1808-1812), la independencia (1822) y los conflictos derivados posteriores. Esto fue tan así que el cura responsable de la parroquia entre 1830 (muerte de Bolívar e independencia de Ecuador respecto de la Gran Colombia) y 1835 , ante la contundencia de las insurgencias y de los movimientos de tropas y de sublevados, se dedicó a explicar en breves crónicas de fin de año algunos de los avatares e inestabilidades que acontecieron en la zona. Dejando constancia de ello, puede indicarse que la revisión y el vaciado nominal -más allá de la mayor o menor pericia de cada párroco- sugiere su validez completa para la mortalidad adulta y parcial para la mortalidad de párvulos, que solo se contabilizó entre 1743-1753 (libros de entierros), 1758-1770 (balances en libros de bautismos) y 1825-1857. Lo conservado en los libros de entierros permite analizar, además de los valores totales y anuales, los ciclos estacionales, la composición por edades (adultos/párvulos), por estado civil al morir (soltería/matrimonio/viudez) y por sexo, además de algunas escasas referencias sobre las causas de la defunción.

\section{Los retos del paisaje}

El tejido humano de la sierra norandina fue -y quizás sigue siendo- tan compacto como para favorecer movimientos de población en circuitos cerrados. En este valle de clima y paisaje extremo las personas se movieron con asiduidad, pero en distancias tan limitadas como las que permitió la dominación colonial de los súbditos. Una mirada a las procedencias de las personas que acabaron sus días, de forma natural o accidental, sepultadas en el cementerio de Toacazo, da una idea sumaria de la importancia de las relaciones de proximidad (véase Mapa 1). Una primera evidencia retrata la situación: en el callejón interandino no se enterraba a casi nadie de la Costa ni de la Amazonía, los entierros habituales eran de personas de la Sierra. A partir de esta constatación fundamental se pueden añadir otras.

La mayoría de los sepelios involucraban a parroquianos, esto es, habitantes del pueblo de Toacazo por nacimiento o matrimonio. Les seguían por relaciones de proximidad, en el complejo tejido que articulaba los difusos límites entre comunidad, pueblo y hacienda, los antaño desplazados desde el asentamiento de Sigchos (125), sede del antiguo obraje en declive, acompañados a gran distancia por los "indios de la parcialidad de Collanas" (24). El resto conformaba un universo plural de pequeños pueblos que indican los principales 
núcleos habitados del Corregimiento de Tacunga (Real Audiencia de Quito), tal y como queda reflejado en el Mapa 1, en el que se observa que numerosos foráneos procedían de un radio menor a 25 kilómetros, y algunos más esporádicos no superaban recorridos de hasta 50 kilómetros de distancia.

Debe indicarse, no obstante, que el registro deja dos categorías indeterminadas: la primera era la de los “montañeses” (57), que seguramente se refería a campesinos mestizos que, radicados en áreas predominantemente indígenas, disponían de tenencias en parcelas de altura. La segunda incluía a los numerosos "forasteros" (227), un grupo clasificatorio muy significativo en situación ambigua, ya que eran población indígena compuesta por migrantes recientes, migrantes por ascendencia (condición heredada) o yanaconas que reemplazaban a la población original diezmada. Al asumir y mantener la condición de forasteros se convertían en un grupo singular que conseguía escapar del tributo o de la mita (SÁNCHEZ ALBORNOZ, 1994, p. 93-98), pero no podían participar ni de los cabildos ni del reparto comunitario de tierras (LAVALLÉ, 2002, p. 113-118). Solo un pequeño grupo de “españoles” (37) culminó sus días en este cementerio andino, muestra de su condición de transeúntes y de sus hábitos de residencia en otras ciudades de mayor envergadura y señorío, como Latacunga o la capital, Quito. Este bloque compacto de población indígena, que se desplazaba por motivos muy variados a través del territorio, vivió de formas diversas los constreñimientos implícitos en el final de una vida, según fueran las categorías en que podían ser agrupados.

\section{MAPA 1}

Procedencia de los forasteros enterrados en la parroquia de San Antonio de Toacazo 1743-1857

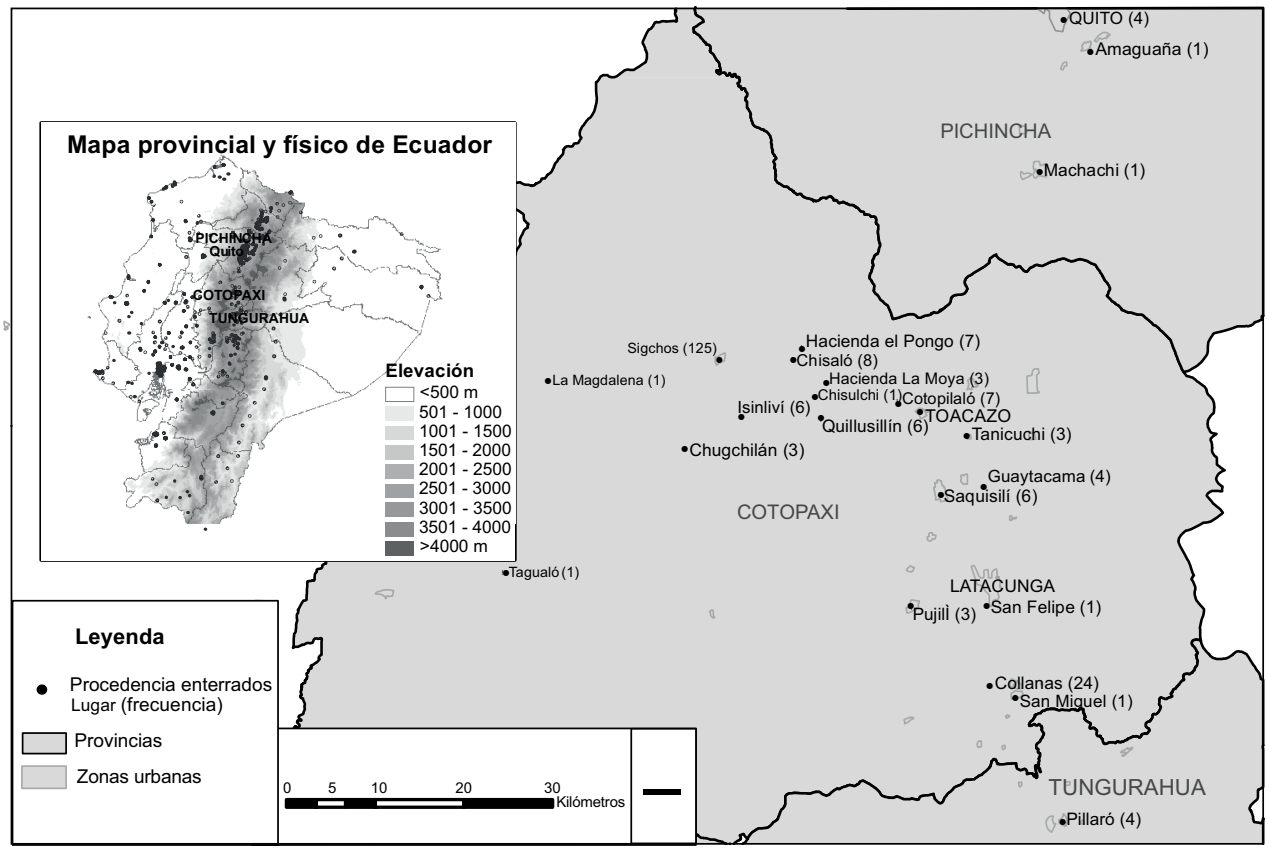

Fuente: APT, libros de entierros (1743-1857), Libro I, Reg. 3C51-90; Libro II, Reg. 3C51-91-83; Libro III, reg. 3C51-92-83; Libro V, Reg. 3C51-94-83; Instituto Cartográfico Militar del Ecuador. 


\section{Estabilidad estacional}

La presencia de estaciones climatológicas en Europa ofrece una información muy interesante en materia demográfica, pero en el Ecuador ello acaba resultando por completo irrelevante. La parroquia de Toacazo se halla en una zona fronteriza entre el clima muy frío e inhóspito del páramo de montaña y el del valle andino mesetario seco. Así, se han establecido y se pueden comprobar características climáticas de la zona que cualquier residente conoce a la perfección. En lo que afecta a los ritmos vitales de las personas, pueden delimitarse períodos de lluvias y de heladas. Por una parte, se presentan dos picos de mayor precipitación: el primero desde febrero a mayo y el segundo, de menor intensidad, entre octubre y diciembre, sumados a tres meses con un total de lluvias significativamente menor (junio, julio y agosto). Por otra parte, las heladas, que se registran en noviembre, diciembre y marzo, y las más fuertes en junio, julio y agosto, se producen por una disminución abrupta de la temperatura durante las noches. En algunas ocasiones se presentan precipitaciones condensadas a manera de hielo que inciden en la viabilidad de los cultivos, llegando algunas veces a provocar la pérdida completa de cosechas. Las heladas y la distribución estacional de las precipitaciones determinan los períodos de siembra y cosecha (BARRAGÁN OCHOA; MIGUEL VALDEZ, 2008, p. 16-18), y con ello los ritmos cotidianos de trabajo y de vida de las personas que habitan la zona, y mucho más, si cabe, de los que trabajan en un entorno de agricultura tradicional.

La incidencia del clima frío, con oscilaciones térmicas extremas entre el día y la noche en los meses de junio, julio y agosto, por una parte, y octubre y noviembre, por la otra, era el rasgo definidor de las fluctuaciones de la mortalidad estacional. Además, como se observa en los Gráficos 1 y 2, este indicador fue mucho más acusado para todas las edades en el siglo xvıI y su línea de trayectoria se suavizó en el xıx. Si el clima marcado por una muy escasa variabilidad no da razón para grandes cambios estacionales, tampoco es relevante introducir el concepto de crisis de subsistencia, en el sentido en que lo definió J. Meuvret en 1946, como instrumento para dilucidar los ciclos de una agricultura que nada tuvo que ver con las carestías derivadas de la dependencia de monocultivos estacionales de cereal en el Antiguo Régimen europeo. En la vecindad de Toacazo se trataba, por el contrario, de una agricultura diversificada en diferentes pisos ecológicos complementarios en los Andes de páramo (MURRA, 1978; SALOMON, 1980; GOLTE, 2001), vertebrados por relaciones económicas pero, sobre todo, sociales, parentales, simbólicas y rituales de reciprocidad “entre iguales” en una "esfera de circulación étnica" (GUERRERO, 1991, p. 267 y ss.). Es decir, en el espacio andino la reciprocidad, salvo situaciones extremas, pudo evitar las hambrunas, ya que en el seno de las haciendas los campesinos habían desarrollado mecanismos de intercambio de los productos que se cultivaban en alturas diferentes, y también de transporte entre lugares relativamente distantes de la hacienda, "incluso a uno o dos días de camino a paso de buen caminante andino” (GUERRERO, 1991, p. 284). 
GRÁFICO 1

Estacionalidad de los entierros en la parroquia de San Antonio de Toacazo

1743-1779

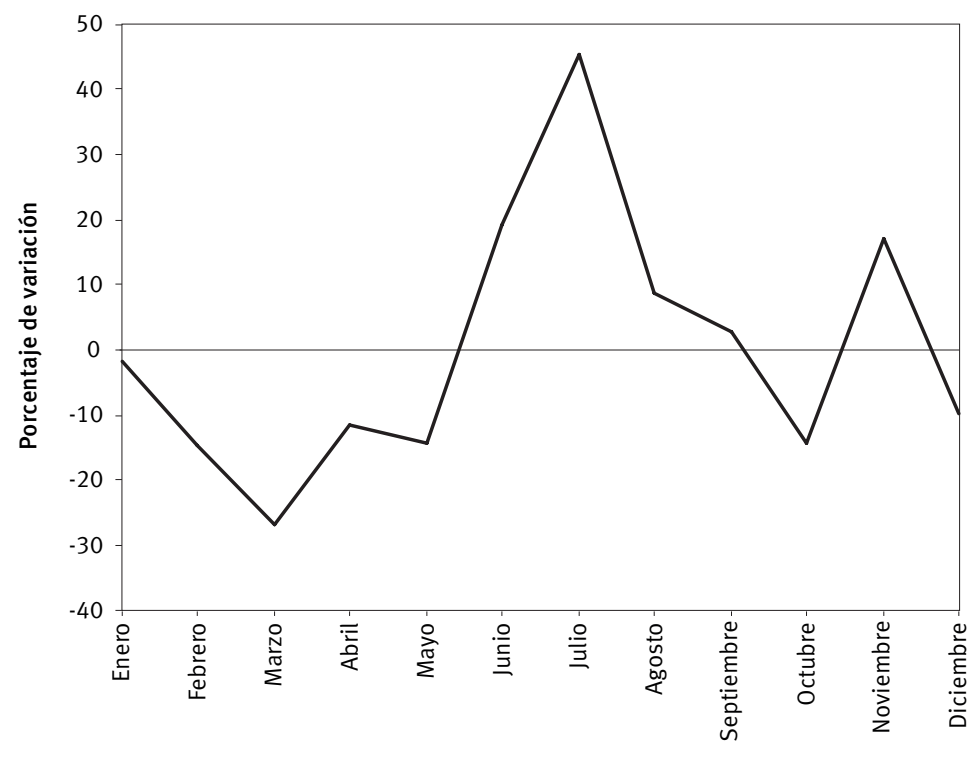

— Variación relativa respecto a la media

Fuente: APT, Entierros (1743-1764), Libro I, Reg. 3C51-90-83; Entierros (1765-1799), Libro II, Reg. 3C51-91-83.

GRÁFICO 2

Estacionalidad de los entierros en la parroquia de San Antonio de Toacazo

1800-1857

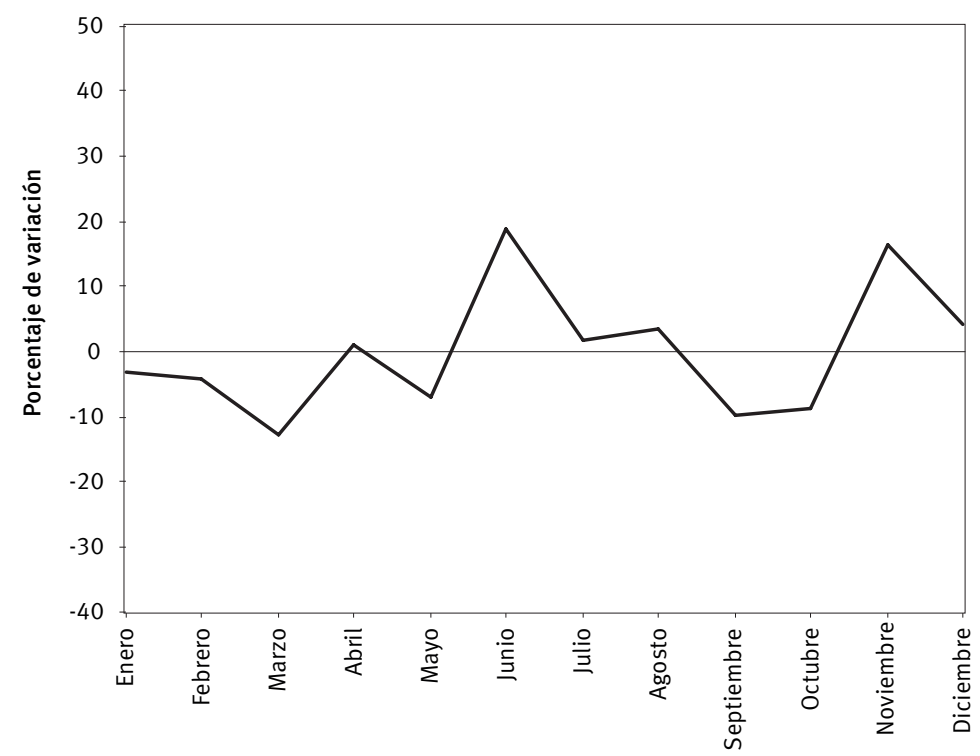

— Variación relativa respecto a la media

Fuente: APT, Entierros (1800-1850), Libro III, Reg. 3C51-92-83; Entierros (1850-1869), Libro V, Reg. 3C51-94-83. 


\section{La fragilidad de la supervivencia infantil}

La supervivencia de los nacidos a lo largo del ciclo demográfico antiguo fue sumamente difícil. El lento vaciado de la documentación parroquial norandina va dejando en la memoria de quien se sumerge en la tarea una sensación de enorme brutalidad en las historias vitales, muy difícil de asumir desde los entornos de bienestar actuales. Se puede observar cómo morían madres de parto y sus hijos recién nacidos en la misma fecha o en jornadas muy próximas; a su vez, revisando los listados, se comprueba cómo numerosas parejas enterraban a varios hijos en un lapso de tiempo breve, cosa que anulaba casi por completo sus posibilidades para engendrar descendencia y ponía en peligro la vida de las madres hasta extremos terribles; se entiende cómo, en años de fiebre, tos y viruela, los párvulos murieran sin tregua, comprometiendo el crecimiento natural de la población, como sucedió en 1831, “año fatal pa los niños; pues el numo de muertos fue un duplo a los nacidos" 3 , y que se documentara la proliferación de abandonos de recién nacidos, expuestos por circunstancias morales o económicas, por lo que no sorprende encontrar expresiones del clérigo del estilo "sepulté a un hijo botado tierno donde F.M. Todo gratis"4. A la postre, un escenario en el que la vida, desde sus inicios, se asemejaba a un lujo.

Las evidencias numéricas son claras, aunque los datos sean inciertos. Los entierros infantiles en San Antonio de Toacazo registran párvulos, esto es, el conjunto compuesto por los menores de un año y, en proporción progresivamente decreciente, de otras cortas edades (1 a 4 años) y de las primeras juveniles (5 a 9 años) (PÉREZ MOREDA, 1980, p. 146). Un índice genérico como el cociente de mortalidad de párvulos -que relaciona sus entierros con los bautismos (HENRY, 1983, p. 98-99)- sugiere, para los años con información disponible, unos resultados suficientemente dramáticos, a pesar de su tendencia a la baja a medida que avanzó el siglo xix. Considerando períodos agrupados en cuatro decenios, entre 1761-1770 el cociente de mortalidad parvularia se cifró en un 457,7\%o; entre $1828-1837$, en $358,2 \%$; entre $1838-1847$, en $366,2 \%$ o, y entre $1848-1857$, en $261,5 \%$ o (los datos a partir de los cuales se obtuvieron estas cifras se exponen en el Anexo 1). A su vez, la representación de los valores anuales es clarificadora de las tendencias, y aunque los años que componen las series de los Gráficos 3 y 4 no abarcan la totalidad del siglo, parece evidente que marcan dos trayectorias bien definidas respecto de las posibilidades de supervivencia infantil.

Así, para el siglo xvIII, el perfil presenta un trazo típico de mortalidad y natalidad de ciclo antiguo, es decir, una fecundidad no influida por el número de hijos precedentes (que algunos definen como natural) y una mortalidad de párvulos tan alta como para comprometer con frecuencia el crecimiento vegetativo de la población, estadística básica que los curas doctrineros encargados del registro constataban habitualmente como aviso para recordar que la reproducción del grupo se encontraba en peligro. Lo que rompe en una y otra línea

\footnotetext{
${ }^{3}$ Cálculo del cura Manuel Ceballos, en APT, Entierros (1800-1850), Libro III, Reg. 3C51-92-83, p. 57d.

4 Inscrito por el cura Manuel Ceballos, 12 de julio de 1837, en APT, Entierros (1800-1850), Libro III, Reg. 3C51-92-83, p. 92 d.
} 
del Gráfico 3 esa cierta estabilidad de comportamientos que expresa la línea polinómica de tendencia fue justamente la epidemia de peste de 1763-1764. Este ciclo fue quizás el último con tal diagnóstico. Se extendió ampliamente por toda la circunscripción y obligó a las autoridades -Cabildo, Audiencia, Corregidores- a tomar medidas tanto para controlar la pulcritud y eficacia de los trabajos de los médicos autorizados -aunque faltaba mucho todavía para la implantación de las primeras políticas salubristas (KINGMAN GARCÉS, 2006, p. 273 y ss.)- como para regular los precios de los suministros de primera necesidad. Esta cuestión abrió un conflicto, entre otros, por el precio del azúcar entre el Cabildo y los jesuitas, principales productores (AUSTIN ALCHON, 1996, p. 162-163). El final de este período, sin datos de ningún tipo que den idea de la magnitud de la mortalidad infantil, transcurrió con unos años extraordinariamente complejos a causa de la proliferación de catástrofes naturales, de la continuidad de los ciclos de enfermedades epidémicas y, sobre todo, por el ambiente de creciente inestabilidad política.

\section{GRÁFICO 3}

Bautismos y entierros de párvulos en la parroquia de San Antonio de Toacazo (1) 1758-1770

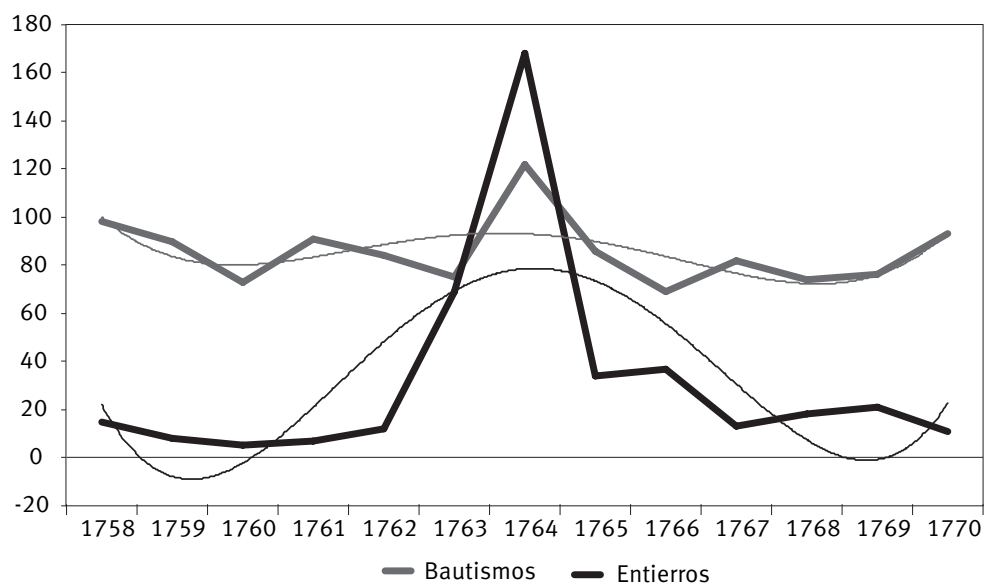

Fuente: APT, Bautismos (1758-1767), Libro III, Reg. 3C51-76-83; Bautismos (1768-1786), Libro IV, Reg. 3C51-75-83 y Entierros (17431764), Libro I, Reg. 3C51-90-83; Entierros (1765-1799), Libro II, Reg. 3C51-91-83.

(1) Valores absolutos y medias móviles de cinco años.

Nota: Los valores absolutos se exponen en el Anexo 1.

Ya para el siglo xIX se pueden intuir, sin forzar la interpretación, dos comportamientos de características ligeramente más próximas al cambio hacia el ciclo demográfico moderno: estabilidad a la baja de la natalidad y tendencia al control, y luego declive, de la mortalidad infantil. En estos años, las autoridades se habían acostumbrado a calificar como epidémico cualquier brote que revistiera cierta importancia, de manera que así se disparaban los mecanismos de un incipiente concepto de salud pública que fue penetrando de la mano de las frágiles reformas derivadas de las políticas del reformismo ilustrado (AUSTIN ALCHON, 1996, p. 169). Los años documentados muestran crisis muy 
notables como las de 1830-1831, 1839-1840 y la más potente de 1849, que afectó de manera simultánea la capacidad reproductiva y la supervivencia. Estas caídas fueron todas consideradas como masivas crisis de "fiebres, tos y viruela", y así lo explicó el sacerdote Manuel de Mora:

La epidemia de biruelas ha hecho un estrago grande en todos los pueblos del Ecuador pues no an podido numerar los muertos con este accidente y yo llebando un apunte prolijo encuentro que an muerto en esta parroquia tanto de biruelas como de otros accidentes el numero de siento treinta y seis 5 .

Además de las epidemias, de los efectos del clima y de los frecuentes accidentes y catástrofes naturales, a medida que avanzó el siglo XIx las variaciones de los indicadores de la mortalidad infantil tuvieron que ver, cada vez más, con una compleja combinación de factores, entre los que debe citarse la importancia tradicional de la lactancia materna, la influencia de los factores económicos y culturales en la crianza de los hijos, los niveles de educación de las madres, la existencia o no de instituciones o redes de protección y bienestar y el desarrollo de la sanidad y la higiene públicas. Todos estos elementos, que en Europa mantuvieron complejas y desiguales trayectorias cronológicas de consolidación como factores coadyuvantes en la reducción de los decesos de los menores (RAMIRO FARIÑAS; SANZ GIMENO, 2000, p. 248-249), eran ignorados por completo en la vida de los habitantes andinos.

\section{GRÁFICO 4}

Bautismos y entierros de párvulos en la parroquia de San Antonio de Toacazo (1) 1828-1857

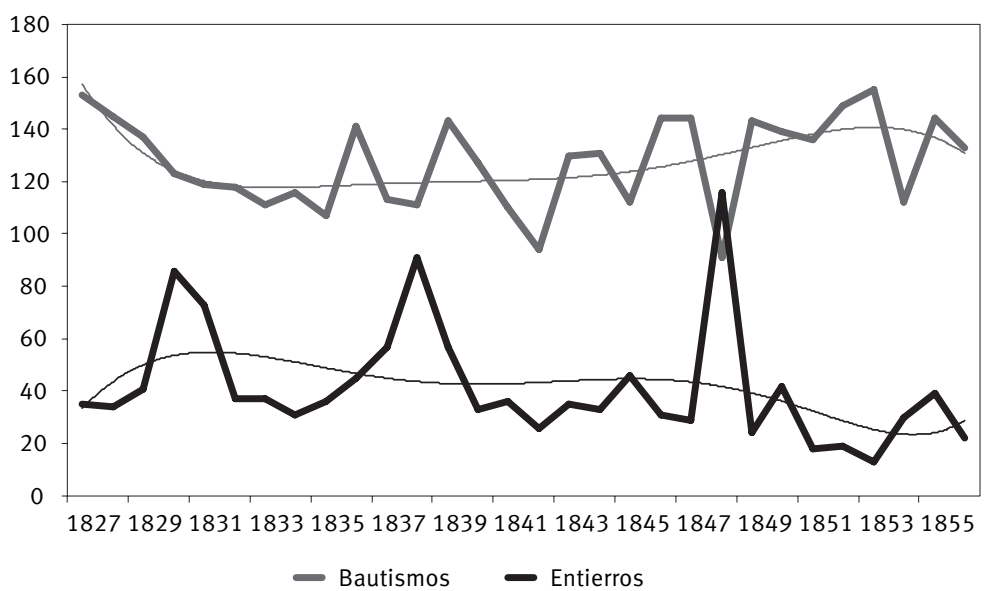

Fuente: APT, Bautismos (1800-1837), Libro VI, Reg. 3C51-78-83, Bautismos (1838-1842), Libro VII, Reg. 3C51-79-83; Bautismos (1843-1850), Libro VIII, Reg. 3C81-80-83; Bautismos (1850-1869), Libro IX, Reg. 3C51-81-83 y Entierros (1800-1850), Libro III, Reg. 3C51-92-83; Entierros (1850-1869), Libro V, Reg. 3C51-94-83.

(1) Valores absolutos y medias móviles de cinco años.

Nota: Los valores absolutos se exponen en el Anexo 1.

\footnotetext{
${ }^{5}$ Manuel de Mora, 31 de diciembre de 1839, en APT, Entierros (1800-1850), Libro III, Reg. 3C51-92-83, p. 107d.
} 


\section{El padecer de los mayores}

En el caso de los adultos, las evidencias de las dificultades se multiplican y los datos que las explican también. Se pueden introducir diversas constataciones que tienen que ver con la trayectoria general de la mortalidad y los diferentes avatares que la influyeron, con su composición por etnia y sexo y sus implicaciones sociales y económicas.

El Gráfico 5 pone de relieve diversas cuestiones, partiendo de una que resulta muy obvia y que tiene que ver con su carácter de gráfico "en dientes de sierra” característico del ciclo demográfico antiguo. Avatares muy diversos incidieron para lograr este aspecto. Primero, cabe fijar la atención en la tendencia, que se trata de un primer espejismo, puesto que alejada de su contexto histórico podría hacer pensar en una transición entre centurias marcada por una suavización de los imperativos de la mortalidad catastrófica. Nada más alejado de la realidad, ya que el infrarregistro de esos años tuvo que ver con la conflictividad política del momento, que ya se ha reseñado. A partir de la Independencia, las necesidades de control social hicieron retomar una confección más recta de los registros parroquiales, y así se perfilan las puntas de defunciones, que alcanzaron extremos de brutalidad en años concretos. Para un observador como el historiador y cronista Juan de Velasco (1727-1792), las principales causas de muerte y decadencia en el Reino de Quito fueron las epidemias, las catástrofes naturales y las revueltas sociales, "a más de esto, han concurrido muchas otras causas para la suma decadencia, no siendo la menor de ellas la grande libertad concedida al comercio con el extranjero" (VELASCO, 1842, p. 42). Cabe ocuparse entonces de la incidencia de las dos primeras, ya que seguramente influyeron en las otras dos.

GRÁFICO 5

Entierros de adultos en la parroquia de San Antonio de Toacazo (1)

1743-1857

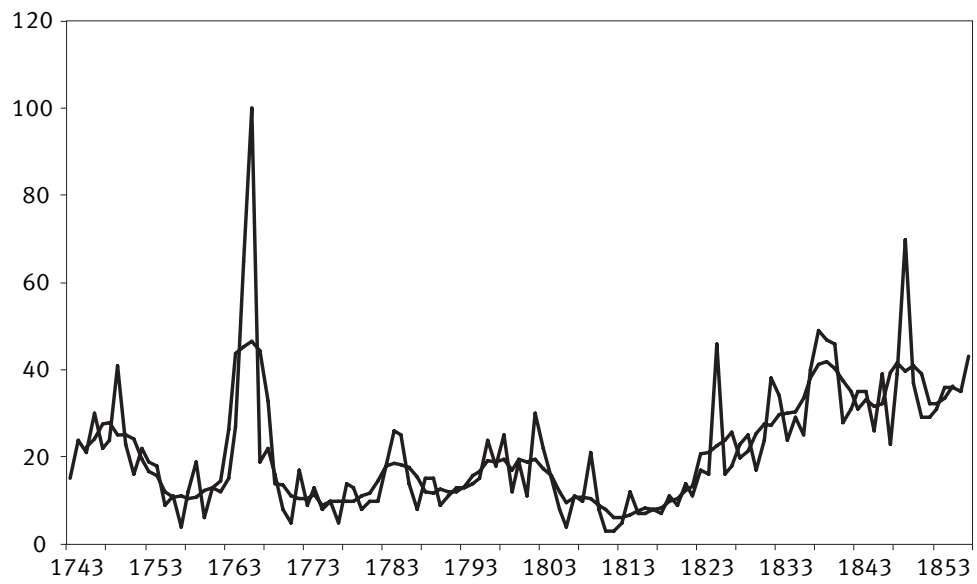

Fuente: APT, Entierros (1743-1764), Libro I, Reg. 3C51-90-83; Entierros (1765-1799), Libro II, Reg. 3C51-91-83; Entierros (1800-1850), Libro III, Reg. 3C51-92-83; Entierros (1850-1869), Libro V, Reg. 3C51-94-83.

(1) Valores absolutos y medias móviles de cinco años.

Nota: Los valores absolutos corresponden a los de entierros de solteros/as, casados/as y viudos/as, según los datos que aparecen en el Anexo 2. 
La continuidad de los ciclos de enfermedad devino abrumadora. Según S. Austin Alchon (1996, p. 161), entre 1700 y 1785 se vivieron 16 períodos críticos, en los que se difundieron peste y peste japonesa, gripe, viruela, sarampión, esquilencia (anginas), disentería y mal de pujos (disentería con sangre), la mayor parte de las veces con enfermedades combinadas. Para el Ochocientos no se dispone de datos oficiales, pero los curas de la parroquia pusieron de manifiesto en numerosas ocasiones la ferocidad de la viruela y de los síntomas que la acompañaban (fiebre y tos), como se dejó asentado en 1833 y en 1839-1840. En la parroquia de Toacazo la información sobre las causas de muerte era extraordinariamente escasa: de los 4.187 entierros oficiados, 2.476 involucraban a personas adultas, y de ellas solo se explicitó la causa de muerte en 186 casos, un 4,4\% sobre el total y un $7,5 \%$ respecto a los decesos de adultos. Una aproximación a esos datos de índole cualitativa acerca, de forma quizás impresionista, a las principales explicaciones que se pudieron ofrecer frente a la omnipresencia de la muerte y a la fragilidad de la vida humana. ¿Qué datos resultaban sugestivos para que los diferentes curas los anotaran?

La gente adulta de la parroquia moría con frecuencia de forma imprevista, extraordinaria, lo que implicaba un apunte que rezaba: "murió repentinamente". La justificación podía expresarse o no, pero solía estar relacionada con problemas diversos. El primero era el parto, causa que se atribuye no tanto porque se indicara siempre de forma explícita, sino porque a veces se anotaba la defunción de una mujer, casada o soltera, y en una partida muy cercana la de su hijo o hija de pocos días. El segundo era la enfermedad súbita no diagnosticada (síncope, cólico violento, fiebre repentina delirante), asunto que los sacerdotes trataban a veces con tintes de cierta incredulidad, como si escondiera muertes de otro tipo, susceptibles de penalización. El tercero contenía causas de muerte de mayor calado social en el mundo de la hacienda, como eran la agresión física vertical (maltratados y azotados por capataces y mayorales), los conflictos horizontales (litigios y peleas entre la indiada o los peones de la hacienda) y los accidentes violentos (aplastados, despeñados, fulminados por un rayo, ahogados). En otro orden, la muerte ordinaria por enfermedad diagnosticada recibía nombres precisos de cuadros bien definidos: se citaba, por supuesto, la viruela (con tos y fiebre), además de tos ferina, apostema interior (tumor), hidropesía (en edades avanzadas), problemas gastrointestinales, vómitos de sangre, ictericia, tabardillo (tifus exantemático), muermo de los caballos (neumonía, necrosis y septicemia), sarna, rabia y mal gálico (sífilis con lepra). En estos años, a veces difíciles, también se documentaron algunos pocos casos extremos de personas extraordinariamente longevas ( 54 casos), que se citaban como “viejas", “muy viejas” y “viejísimas” (de más de 80, 90 o incluso 100 años en adelante), de “vida larga" y "edad provecta".

El ciclo vital, no obstante, también estaba sujeto a los caprichos de la naturaleza, máxime en una zona en la que los volcanes eran y son la más imponente presencia paisajística y, por ello, se consideraban divinidades. De acuerdo con tradiciones pre-incaicas estos volcanes, los Apus, tutelaban a las personas tanto en la vida -la dependencia del agua que fluye de las cumbres y riega los valles- como en la muerte -lo imprevisible y 
devastador de temblores, terremotos, erupciones y otras accidentadas variantes. A veces, aunque no siempre a fuerza de costumbre y rutina frente a los cataclismos, los párrocos dejaban pinceladas de crónica para narrarlos, y lo mismo sucedía en instancias políticas más altas y en explicaciones de historiadores coetáneos ${ }^{6}$.

Resulta muy interesante constatar que las tragedias -y la hecatombe que causaban- provocaban efectos sociales más allá de la destrucción material y humana. Para los diferentes poderes coloniales, con frecuencia con intereses contrapuestos, cuando no directamente enfrentados, oficializar la devastación -a manera de declaración de zona catastrófica- implicaba la necesidad de buscar vías de escape que permitieran conculcar el orden impositivo establecido. Por ejemplo, durante el terremoto de 1757 , la magnitud de los daños relatados por el Marqués de Maenza -apoderado del lugar de Latacunga- al monarca Carlos III hizo que, previa consulta al Consejo de Indias, se autorizara en 1758 un notable alivio fiscal que implicaba la exención de impuestos a los vecinos -tributos dentro de los que se incluían la alcabala y todas las demás contribuciones reales- por un plazo de diez años; la exoneración del pago de los réditos de censos por seis años a los afectados; la reducción de los impuestos de censos de las haciendas, de un $5 \%$ a un $3 \%$, y finalmente la suspensión de la tributación de los indios, también por un período de seis años (Nieto, 1999).

El inmediato y notable declive de la recaudación impulsó al Marqués de Selva Alegre, presidente de la Audiencia de Quito, a informar al rey que lo narrado eran exageraciones interesadas animadas por la voracidad impositiva de su autor, dueño de más de 30 fincas, a quien replicó exponiendo que casi nadie se vio afectado, excepto conventos, iglesias y casas de fábrica (clero y nobleza), puesto que los lugareños vivían en casas de cuatro cañas que resistieron o, por su escaso valor, se reconstruyeron ${ }^{7}$. En 1765 el Rey ordenó que se revisara el expediente y se actuara en consecuencia a partir de la veracidad o no de lo expuesto. Las autoridades aprovecharon la catástrofe para enriquecerse a costa de un supuesto alivio fiscal para los habitantes de la zona, y las versiones contrapuestas abrieron un litigio que se estancó varios años antes de resolverse, aunque mientras tanto alguien siguió recaudando, y los de siempre tributando.

Para ellos, los de siempre, humildes peones conciertos, la escenografía de los peligros seguía siendo un lugar común. Se escribieron en los registros, por ejemplo, expresiones tan elocuentes como "un temblor grande de cerca de un minuto de noche en marzo" (1830); “este año hubo tres temblores medianos, otro más fuerte” (1832); "treinta y cinco temblores terribles alrededor de Iliniza [...] Uno el 28 de mayo que casi arruina el pueblo:

\footnotetext{
$\overline{6}$ En 1789 Juan de Velasco (1842, p. 80-86) documentaba erupciones en un ciclo seguido entre 1742, 1743, 1744 y 1746 , luego en 1766 y, por fin, la "horrenda" de 1768; respecto de los terremotos destacaba dos grandes sismos: el devastador de 1699 y el de 1757, con una amplitud de seis meses de duración. En las cubiertas de los libros de bautismos de 1768-1786 y 1838-1842 el párroco de turno dibujó en cada uno un humeante volcán.

${ }^{7}$ Esta versión coincide con la narrada por Juan de Velasco, quien indicaba que el terremoto tuvo réplicas durante más de seis meses y que los muertos fueron 400, "aunque se decían pasar de 2.000 " (1842, p. 85). El balance fue tremendo: "Las continuadas desgracias que ha padecido este lugar en los tiempos modernos, y la decadencia del comercio que tenía, han hecho que las ruinas queden sin más reparos que los precisos para poder vivir” (1842, p. 86).
} 
¡Qué año tan horrible!" (1835) o “llovió tierra [...]: Dios se compadezca de sus criaturas" $(1843)^{8}$, y acertaba el cura, porque las dificultades derivadas de los desastres siguieron cebándose en la comunidad, en esas "criaturas" que él se empeñaba en proteger y, a su vez, en seguir manteniendo bajo control. Una vigilancia que se ejerció sobre la realidad y sobre la picaresca de la miseria, ya que en ocasiones también la feligresía buscó vías de escape. Las encontraron en la posibilidad de declararse pobres en el momento de enterrar a un familiar (o recibir cualquier otro sacramento), y así obtener la caridad eclesiástica para gozar de sepelio (ceremonial y ataúd) gratuito. Llegó a ser tanto el abuso en años difíciles que los mismos sacerdotes detectaron y prohibieron la exención de pago, nombrando recaudadores locales, conocedores exactos de los bienes de cada quien, "a fin de que la Iglesia no se perjudique a fuerza de tanto entierro gratis" .

Pero ¿quién componía esta pauperizada feligresía?, ¿qué rasgos identificaban algunas de sus estadísticas vitales básicas en relación con la mortalidad? La primera información disponible deriva del estado civil de los fallecidos, dato que por una parte ofrece una muy somera indicación de tendencia evolutiva y, por la otra, más interesante, una aproximación a la edad de las personas al morir.

Parece obvio observar, en primer lugar, que la estabilidad de las trayectorias de la soltería, el matrimonio y la viudez se mantuvo en estos años cruciales (entre 1743 y 1857). Las líneas de tendencia polinómica que se observan en el Gráfico 6 muestran que en ningún momento un estado civil se sobrepuso o decayó frente a otro en su transcurrir secular, y que ello fue así hasta el final, más allá de la cuarta década del siglo xıx, cuando se intuye que algo pudo empezar a cambiar en relación con las acometidas de la mortalidad catastrófica. A simple vista se puede verificar que, para ambos sexos, se redujo el número de defunciones de casados -los más numerosos en la línea superior- y solteros -línea intermedia-, y se prolongaron las expectativas vitales de los viudos -la línea inferior-, comportamiento que se manifestó cuando ya se había producido el gran cambio político desde la Independencia hacia la instauración de la República del Ecuador, efeméride que, año a año, se indicaba en los registros. Esta posible mejora de las condiciones de subsistencia, que implicó un alargamiento de la vida de las personas adultas, es un asunto de gran calado que precisa de ulteriores investigaciones, ya que no solo implica reflexionar sobre las cronologías locales de la transición demográfica ${ }^{10}$, sino también sobre qué continuidades y qué cambios marcaron la vida cotidiana de las personas en el largo trayecto de la conclusión formal del régimen colonial.

\footnotetext{
${ }^{8}$ APT, Bautismos (1800-1837), Libro VI, Reg. 3C51-78-83, pp. 193r, 238d, 272d, y Bautismos (1843-1850), Libro VIII, Reg. 3C81-80-83, s.f.

${ }^{9}$ Luis Ceballos, 13 de abril de 1856, en APT, Entierros (1850-1869), Libro V, Reg. 3C51-94-83, p. 16r.

${ }^{10}$ Sobre una categorización a escala mundial, propuesta por D. S. Reher, que sitúa los diferentes países en grupos según la fecha aproximada en que emprendieron el proceso de transición demográfica -agrupados como forerunners (pioneros), followers (seguidores), trailers (rezagados) y latecomers (retrasados) -, Ecuador se podría incluir entre los trailers, ya que inició ese proceso entre 1915-1919 y el declive de la fertilidad en 1970 (Reher, 2004, p. 38), fechas que quedan muy alejadas de la cronología de los datos de esta investigación.
} 
GRÁFICO 6

Estado civil de la feligresía enterrada en la parroquia de San Antonio de Toacazo (1) 1743-1857

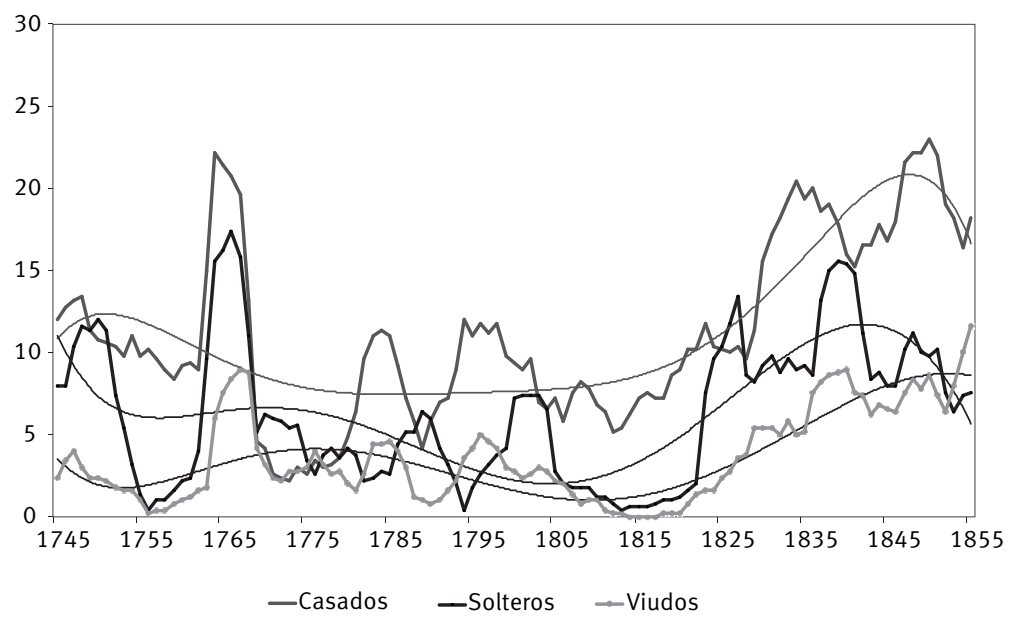

Fuente: APT, Entierros (1743-1764), Libro I, Reg. 3C51-90-83; Entierros (1765-1799), Libro II, Reg. 3C51-91-83; Entierros (1800-1850), Libro III, Reg. 3C51-92-83; Entierros (1850-1869), Libro V, Reg. 3C51-94-83.

(1) Medias móviles de cinco años y polinómicas de seis.

Nota: Los valores absolutos corresponden a entierros de solteros/as, casados/as y viudos/as, según datos que aparecen en el Anexo 2.

La segunda observación que se puede inferir a partir de lo que explicita el Gráfico 6 es que, entre aquellos y aquellas que habían alcanzado la edad adulta, la mayor incidencia de la mortalidad recaía sobre las personas de edad media casadas, es decir, mujeres que se encontraban en la madurez de la etapa reproductiva y a pleno rendimiento en el sostenimiento de las economías familiares, y hombres que estaban inmersos en la vida laboral, ya en la hacienda, ya en el obraje. Esta constatación tiene implicaciones sociales muy profundas, porque este fue el grupo etario al que más le afectaron la muerte repentina y la muerte violenta -tal como se describieron con anterioridad-, y ambas estuvieron vinculadas de forma atávica a la dureza de las condiciones de trabajo campesino, tanto por las implicaciones vitales impuestas por un entorno de alta montaña como sobre todo por la contundencia de las formas de explotación impuestas por los hacendados y sus mayordomos y mayorales.

El análisis de los casos particulares descritos en la documentación lleva, uno a uno y sin solución de continuidad, a dibujar un retrato cruel de las condiciones de vida de los indígenas. No obstante, más allá de las percepciones impresionistas que pudieran desprenderse de lo que se detalló hace tantos años en un conjunto de 4.187 partidas de defunción y entierro, resulta imprescindible cuantificar las dimensiones de la tragedia. Una primera aproximación implica detallar qué personas y en qué número estuvieron involucradas en estos acontecimientos (véase Tabla 2). 
TABLA 2

Entierros por etnia y sexo en la parroquia de San Antonio de Toacazo 1743-1758

\begin{tabular}{|c|c|c|c|c|c|c|c|}
\hline \multirow[b]{2}{*}{ Período } & \multicolumn{3}{|c|}{ Hombres } & \multicolumn{3}{|c|}{ Mujeres } & \multirow[b]{2}{*}{ Otros(1) } \\
\hline & Españoles & $\begin{array}{l}\text { Blancos/ } \\
\text { Mestizos } \\
\text { locales }\end{array}$ & Indios & Españolas & $\begin{array}{c}\text { Blancas/ } \\
\text { Mestizas } \\
\text { locales }\end{array}$ & Indias & \\
\hline Siglo XVIII & 6 & 28 & 598 & 4 & 31 & 594 & - \\
\hline Siglo xIX & 14 & 147 & 1.375 & 13 & 107 & 1.267 & 3 \\
\hline Total & 20 & 175 & 1.973 & 17 & 138 & 1.861 & 3 \\
\hline
\end{tabular}

Fuente: APT, Entierros (1743-1764), Libro I, Reg. 3C51-90-83; Entierros (1765-1799), Libro II, Reg. 3C51-91-83; Entierros (1800-1850), Libro III, Reg. 3C51-92-83; Entierros (1850-1869), Libro V, Reg. 3C51-94-83.

(1) Corresponde a la familia Rubio, proveniente de Quito, compuesta por Mariano, mulato, casado con Damacia Villalba (enterrado el 16 de octubre de 1829); Dorotea, negra, viejísima y viuda (enterrada el 26 de septiembre de 1829) y Antonia, zamba, ya de Toacazo, esclava de la señora Francisca Maldonado y enterrada de caridad (27 de mayo de 1839).

Por estas fechas Toacazo era una parroquia habitada por una mayoría de población indígena ( $91 \%$ de indios frente a un $9 \%$ de blancos-mestizos y $92,1 \%$ de indias frente a un $7,9 \%$ de blancas-mestizas). Con el correr de los años esta incontestable realidad cambió de forma natural e institucional, hasta transformarse en una ciudad blanco-mestiza en los tiempos del sistema social racializado del gamonalismo, esto es, la forma de poder político rural resultante de la vigencia de una estructura estamental o de castas en la que se había naturalizado la dominación étnica (IBARRA, 2002, p. 493). Las implicaciones que se derivaban de esta composición explican algunas desigualdades en el momento de morir, a todas luces interesantes. El resultado de correlacionar estadísticamente las categorías que se refieren a sexo y etnia frente a los estragos de la mortalidad total habla de forma bien explícita de ello.

Así, ensayando cálculos sobre estas magnitudes, se pueden establecer algunas correlaciones muy sencillas que permiten constataciones obvias ${ }^{11}$. La primera es que los blancos podían llegar a escaparse mejor (o más fácilmente) de un episodio catastrófico que los indios, ya fuere porque se protegían de las epidemias desplazándose a quintas y residencias aisladas -como en Europa-, ya fuere porque ninguno de ellos estaba sujeto a la dureza laboral de la vida en la hacienda. La segunda es que no había diferencias significativas en la mortalidad diferencial por sexo $0^{12}$, realidad que, con toda seguridad, estaba relacionada con las formas de trabajo compartidas por ambos congéneres. No obstante, se puede observar que en el siglo XIX se inició una suavización ligera de los decesos femeninos, lo que bien pudo deberse a una moderación de la incidencia de los factores de riesgo adicional que

\footnotetext{
$\overline{11}$ Los cálculos propuestos parten de aplicar la correlación de Pearson a series emparejadas, a fin de comprobar su comportamiento. Los datos correlacionados son: $1 /$ total de muertes y muertes de indios $\left(\rho_{x, y}=99,3 \%\right) ; 2 /$ total de muertes y muertes de blanco-mestizos $\left(\rho_{x, y}=72 \%\right) ; 3 /$ muertes de blanco-mestizos y muertes de indios $\left(\rho_{x, y}=64,6 \%\right) ; 4 /$ total de muertes y muertes de varones $\left(\rho_{x, y}=92,2 \%\right) ; 5 /$ total de muertes y muertes de mujeres $\left(\rho_{x, y}=95,8 \%\right)$, y $6 /$ muertes de hombres y muertes de mujeres $\left(\rho_{x, y}=77,2 \%\right)$.

${ }^{12}$ Los datos indican que no hubo mortalidad diferencial por razón de sexo a lo largo del período estudiado (107 varones por cada 100 mujeres). La segregación de datos por centurias permite observar una ligera tendencia a la suavización de la mortalidad femenina. Así, para el siglo xvIII, la relación de mortalidad entre hombres y mujeres fue idéntica (632 hombres/629 mujeres $=1,004 \%$ ), y en el siglo XIX se puede observar una ligera sobremortalidad masculina (1.536 hombres/1.390 mujeres $=1,105 \%$ ), cifrada en que por cada 100 decesos femeninos se producían 110 masculinos.
} 
asumían las mujeres derivados de su función reproductiva, tantas veces comprometida además por la notable mortalidad de párvulos. Dicho en otros términos, en Toacazo, y por extensión en el mundo andino, no parecía ni fácil ni probable que sus habitantes, por más espacios de ritual que pudieran crear al margen de la parroquia, soñaran con escenarios de "buen vivir" -a la manera del supuestamente ancestral Sumak Kawsay quichua, tan de moda hoy-, de la misma forma que no los imaginaron sus coetáneos europeos (VILALTA, 2007, p. 57-62).

\section{Recapitulación. Historia demográfica como historia social}

Quizás los estragos causados por la mortalidad han sido una excusa para reflexionar sobre el lado más agreste de la vida indígena en los Andes en tiempos coloniales, algo que cualquier persona que transite por la zona puede verificar aún hoy. La proliferación de exvotos en las iglesias rurales, a veces con pinturas de gran expresividad que representan escenas tan trágicas como las expuestas en las líneas precedentes, o la simple contemplación de recónditas, minúsculas y empinadas parcelitas de papas al cuidado de mujeres y su pequeña prole, invitan a pensar en las dificultades del pasado y en las permanencias en el presente. El paisaje, el entorno y numerosas realidades sociales y económicas impresionan a quien las observa desde miradas acostumbradas a otras latitudes, a otras condiciones de vida.

Tales tejidos de relaciones formaban parte de un mundo complejo y oculto en el que "la coerción de todo tipo era parte de la vida cotidiana de las haciendas, aunque la violencia de unos y el consentimiento de otros constituían relaciones o estrategias complementarias" (BRETÓN, 2012, p. 62). Es en este doble juego en el que, curiosamente, las estadísticas de la muerte retratan una imagen crucial en el devenir histórico de los pobladores de estas tierras.

Esbozada con la imperativa categoricidad que los datos confieren a una representación gráfica que resume los entierros a partir de los dos grandes grupos de clasificación étnica en el Ecuador después de la Independencia, se observa una clara imagen de la forma en que se disolvió el mundo colonial y se impuso, lentamente, la nueva república ciudadana (véase Gráfico 7). Bajo el dictado y al amparo de las Leyes de Indias, la población de la Real Audiencia de Quito devino tributaria y por ello, afincados en una unidad administrativa como una parroquia de hacienda, el conjunto de sus habitantes necesariamente debía inscribirse como indígena. Esto fue así de forma objetiva, por la composición étnica mayoritaria, pero también por lo que se desprendía de la observación interesada (subjetiva) de los administradores, ávidos de recaudación: se precisaban indios tributarios. A partir de la Independencia los registros de fallecidos muestran, además de las dramáticas incidencias estrictamente demográficas antes descritas, el incremento del grupo de los hombres y mujeres blanco-mestizos, tanto por el crecimiento natural de sus integrantes -difusión del proceso de mestizaje en el transcurso secular-como por la precisión con que los redactores de las fuentes parroquiales comenzaron a perfilar, con enorme finura, las categorías étnicas 
de inscripción. Aparecieron así, con preocupación permanente para que nadie quedase exento de pertenencia a una u otra tipología, instrumentos clasificatorios minuciosos que como nunca antes se referían a los fallecidos como españoles/as, blancos/as de primera, blancos/as de segunda, mestizos/as, medio mestizos/as e indios/as, y todo ello en un entorno en el que la continuidad inamovible e inalterable de los apellidos -esto es, de las familias- resultaba completamente abrumadora.

GRÁFICO 7

Entierros por etnia en la parroquia de San Antonio de Toacazo 1743-1857

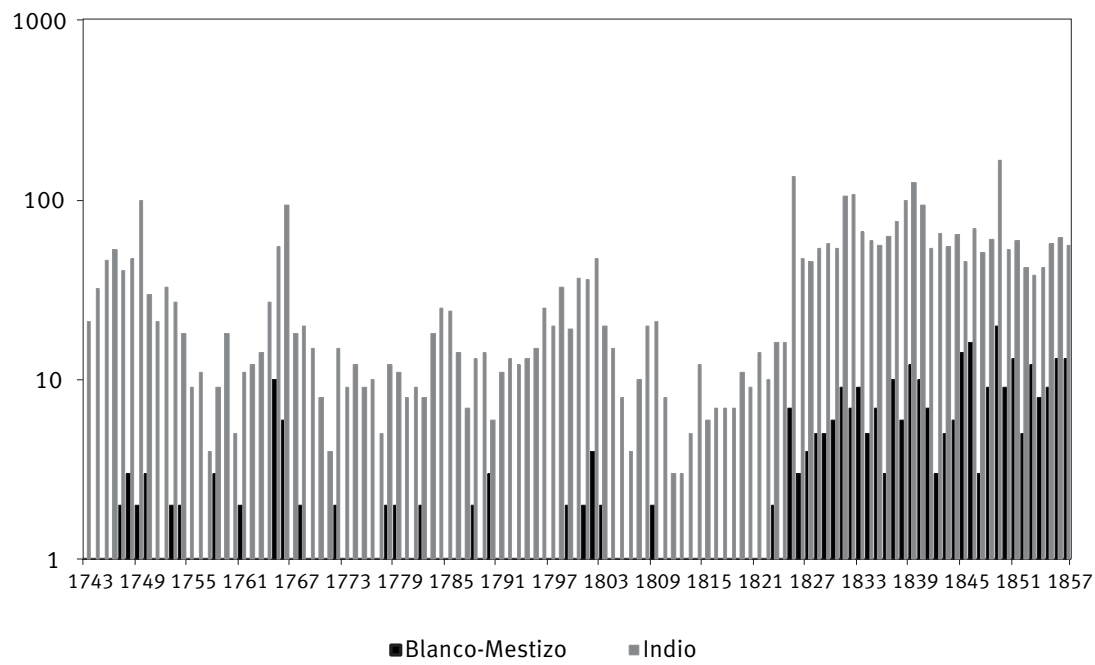

Fuente: APT, Entierros (1743-1764), Libro I, Reg. 3C51-90-83; Entierros (1765-1799), Libro II, Reg. 3C51-91-83; Entierros (1800-1850), Libro III, Reg. 3C51-92-83; Entierros (1850-1869), Libro V, Reg. 3C51-94-83. Nota: Los valores absolutos se exponen en el Anexo 2.

¿Qué sucedió? Pues que frente a la inmutabilidad de un universo indígena con una presencia mínima de blancos recién llegados de la metrópoli en tiempos de la colonia, el lento proceso que llevó al final del tributo de indios en 1857 supuso, primero, la necesidad de eliminar una forma de protección - paternalista, diría E. P. Thompson- hacia un grupo, los indígenas - algunos de cuyos miembros pudieron quizás traspasar la frontera étnica-, y segundo, conllevó la urgencia por crear un nuevo y amplio cuerpo tributario blanco-mestizo que pudiera, en casos de antigua raigambre en la comunidad, vincularse a los nuevos poderes rurales locales. De manera progresiva, el resultado dejó a la sociedad indígena minimizada y reducida a una nueva forma de marginalidad excluyente y de larga duración, y no ha recuperado su voz y protagonismo sino hasta fechas muy recientes.

\section{Referencias}

ANDRIEN, K. J. The Kingdom of Quito, 1690-1830. The state and regional development. Cambridge: Cambridge University Press, 2002. 
AUSTIN ALCHON, S. Sociedad indígena y enfermedad en el Ecuador colonial. Quito: Editorial Abya-Yala, 1996.

BARRAGÁN OCHOA, F.; MIGUEL VALDEZ, F. Dinámicas agrarias y avance de la frontera agrícola en el sector de Wintza, parroquia Toacazo. Disertación inédita. Quito: Pontificia Universidad Católica del Ecuador, 2008.

BRETÓN SOLO DE ZALDÍVAR, V. Toacazo: en los Andes equinocciales tras la reforma agraria. Quito: FLACSO, Sede Ecuador - Editorial Abya-Yala, Universitat de Lleida, 2012.

BRINES TYRER, R. Historia demográfica y económica de la Audiencia de Quito: población indígena e industria textil 1600-1800. Quito: Banco Central del Ecuador, 1988.

CHATURVEDI, V. (Ed.). Mapping subaltern studies and the postcolonial. London y New York: New Left Review y Verso, 2000.

GOLTE, J. Cultura, racionalidad y migración andina. Lima: Instituto de Estudios Peruanos, 2001.

GUERRERO, A. La semántica de la dominación: el concertaje de indios. Quito: Libri Mundi, 1991.

Administración de poblaciones, ventriloquía y transescritura. Análisis históricos: estudios teóricos. Lima: Instituto de Estudios Peruanos/FLACSO Ecuador, 2010.

HENRY, I. Manual de demografía histórica. Técnicas de análisis. Barcelona: Crítica, 1983.

IBARRA, H. Origen y decadencia del gamonalismo en la Sierra ecuatoriana. Anuario de Estudios Americanos, tomo LIX, 2, p. 491-510, 2002.

KAY, C. Desarrollo comparativo del sistema señorial europeo y del sistema de haciendas latinoamericano. Anuario de Estudios Americanos, XXXI, p. 681-723, 1974.

KINGMAN GARCÉS, E. La ciudad y los otros: Quito, 1860-1940. Higienismo, ornato y policía. Quito: FLACSO, sede Ecuador, Universitat Rovira i Virgili, 2006.

LAVALLÉ, B. Al filo de la navaja: luchas y derivas caciquiles en Latacunga (1730 - 1790). Quito: Corporación Editora Nacional, 2002.

LIVI BACCI, M. Conquista. La distruzione degli indios americani. Bologna: Il Mulino, 2005.

LUCENA SALMORAL, M. Quito. En: VV. AA. Historia de Iberoamérica. Tomo II: Historia Moderna. Madrid, Cátedra, 2007, p. 486-490.

LYONS, B. J. Remembering the Hacienda. Religion, authority, and social change in highland Ecuador. Austin: The University of Texas Press, 2006.

MURRA, J. V. La organización económica del estado inca. México: Siglo xxı,1978.

PUCP, 2002.

. El mundo andino: población, medio ambiente y economía. Lima: Fondo Editorial

NEWSON, L. A. Life and death in early colonial Ecuador. Norman: University of Oklahoma Press, 1995.

NIETO, M. V. Terremoto en 1757. El Tiempo.com, Archivo. Bogotá: El Tiempo Casa Editorial, 1999. Disponible en: 〈http://www.eltiempo.com/archivo/documento/MAM-857445〉. Acceso en: mayo 2013.

PÉREZ MOREDA, V. Las crisis de mortalidad en la España interior (siglos XVI-XIX). Madrid: Siglo XXI Editores, 1980.

POLONI-SIMARD, J. El mosaico indígena: movilidad, estratificación social y mestizaje en el corregimiento de Cuenca (Ecuador) del siglo XVı al XVIII. Quito: Editorial Abya-Yala, 2006. 
QUISHPE BOLAÑOS, J. M. Transformación y reproducción indígena en los Andes septentrionales. Los pueblos de la provincia de Sigchos, siglos XVI y XVII. Quito: Editorial Abya-Yala, 1999.

RAMIRO FARIÑAS, D.; SANZ GIMENO, A. Childhood mortality in Central Spain, 1790-1960: changes in the course of demographic modernization. Continuity and Change, n. 15, p. 235-267, 2000.

RAMÓN VALAREZO, G.; TORRES DÁVILA, V. H. El desarrollo local en el Ecuador: historia, actores y métodos. Quito: Editorial Abya-Yala, 2004.

REHER, D. S. The demographic transition revisited as a global process. Population, Space and Place, n. 10, p. 19-41, 2004.

SALOMON, F. Los señores étnicos de Quito en la época de los incas. Otavalo: Instituto Otavaleño de Antropología-Editorial Gallocapitán, 1980.

SÁNCHEZ ALBORNOZ, N. La población de América Latina. Desde los tiempos precolombinos al año 2025. Madrid: Alianza Universidad, 1994.

SLICHER van BATH, B. Hispanoamérica en torno a 1600. Alicante: Publicaciones de la Universidad de Alicante, 2010.

VELASCO, J. de. Historia del reino de Quito en la América Meridional, Tomo III y Parte III La historia moderna. Quito: Imprenta de Gobierno por Juan Campuzano, 1842 (original de 1789).

VILALTA, M. J. La construcción histórica del concepto de ciudadanía: un impactante viaje entre Europa y América (siglos xVI-xVIII). En: BRETÓN, V.; GARCÍA, F.; JOVÉ, A.; VILALTA, M. J. (Eds.). Ciudadanía y exclusión: Ecuador y España frente al espejo. Madrid: Los Libros de la Catarata, 2007, p. 33-76.

WACHTEL, N. Los vencidos. Los indios del Perú frente a la conquista española (1530-1570). Madrid: Alianza Editorial, 1976.

\section{Sobre la autora}

María José Vilalta es doctora en Geografía e Historia-Historia Moderna por la Universitat de Barcelona. Se desempeña como Profesora Titular de Historia Moderna en el Departament d'Història de l’Art i Història Social, Facultat de Lletres, Universitat de Lleida.

\section{Dirección de correo}

Plaça de Víctor Siurana, 1

25003 Lleida - España

\section{Resumo}

Morte nos Andes: sociedade colonial e mortalidade nas fazendas andinas (Equador, 1743-1857)

A vida cotidiana nas fazendas coloniais implicou a introdução de uma forma de administração de populações imposta sobre a sociedade indígena e regulada pelas Leyes de Índias. Na zona norte dos Andes, o concertaje de índios e a abundância de trabalhos na agricultura e nos obrajes (manufactura têxtil) constituíram fatores de atração que permitiram verificar um crescimento em longa duração da população. Este estudo analisa, mais do que o debate inconclusivo sobre a catástrofe demográfica das populações indígenas, os perfis e a incidência da mortalidade 
ordinária e catastrófica como fator de regulação do crescimento de uma paróquia rural na etapa final dos tempos coloniais. A investigação tem por base o levantamento completo dos registos paroquiais (enterros). Os dados sobre mortalidade analisados abrangem o período entre os primeiros anos da fundação da paróquia e a supressão do tributo indígena em 1857, ano em que se encerra a análise, apesar da continuidade dos registros. As evidências mostram uma realidade marcada por uma mortalidade típica dos ciclos antigos, dominada pelas condições de vida e trabalho adversas que marcavam a vida na fazenda, sendo que os dados possibilitam observar o universo das rígidas categorias sociais do mundo colonial.

Palavras-chave: Mortalidade. População indígena. Regime de fazenda. América colonial. Andes do Equador.

\section{Abstract \\ Death in the Andes: colonial society and mortality in the Ecuadorian haciendas (Ecuador, 1743-1857)}

The implementation of the hacienda system involved the introduction of the administration of populations imposed on the indigenous society by means of Leyes de Indias. In the NordAndean area, the Indian concertaje, joined to the abundance of jobs in peasant tenures and in the obrajes (textile workshops), were to be pull factors to verify a long-term population growth. This study focuses on the profiles and on the incidence of mortality as a factor of growth control in an hacienda parish at the end of Colonial Era. The research is based on the parish registers (burials). The mortality data comes from a register dated between the years when the parish was established until the abolition of Indian tribute in 1857, as the final year of observation despite the register is still continued. Evidence shows a mortality of ancient cycle, strongly determined by the hard work conditions in the hacienda and the data provide an illuminating insight into the rigid social classifications in the Colonial world

Keywords: Mortality. Indigenous population. Colonial Latin America hacienda system. Ecuadorian Andes. 


\section{Anexo 1}

Datos para el cálculo de la mortalidad de párvulos por décadas, parroquia de San Antonio de Toacazo 1758-1770 y $1828-1857$

\begin{tabular}{|c|c|c|}
\hline Año & Bautismos & Defunciones de párvulos \\
\hline 1758 & 98 & 15 \\
\hline 1759 & 90 & 8 \\
\hline 1760 & 73 & 5 \\
\hline 1761 & 91 & 7 \\
\hline 1762 & 84 & 12 \\
\hline 1763 & 75 & 69 \\
\hline 1764 & 122 & 168 \\
\hline 1765 & 86 & 34 \\
\hline 1766 & 69 & 37 \\
\hline 1767 & 82 & 13 \\
\hline 1768 & 74 & 18 \\
\hline 1769 & 76 & 21 \\
\hline 1770 & 93 & 11 \\
\hline 1828 & 153 & 35 \\
\hline 1829 & 145 & 34 \\
\hline 1830 & 137 & 41 \\
\hline 1831 & 123 & 86 \\
\hline 1832 & 119 & 73 \\
\hline 1833 & 118 & 37 \\
\hline 1834 & 111 & 37 \\
\hline 1835 & 116 & 31 \\
\hline 1836 & 107 & 36 \\
\hline 1837 & 141 & 45 \\
\hline 1838 & 113 & 57 \\
\hline 1839 & 111 & 91 \\
\hline 1840 & 143 & 57 \\
\hline 1841 & 127 & 33 \\
\hline 1842 & 110 & 36 \\
\hline 1843 & 94 & 26 \\
\hline 1844 & 130 & 35 \\
\hline 1845 & 131 & 33 \\
\hline 1846 & 112 & 46 \\
\hline 1847 & 144 & 31 \\
\hline 1848 & 144 & 29 \\
\hline 1849 & 91 & 116 \\
\hline 1850 & 143 & 24 \\
\hline 1851 & 139 & 42 \\
\hline 1852 & 136 & 18 \\
\hline 1853 & 149 & 19 \\
\hline 1854 & 155 & 13 \\
\hline 1855 & 112 & 30 \\
\hline 1856 & 144 & 39 \\
\hline 1857 & 133 & 22 \\
\hline
\end{tabular}

Fuente: Libros de bautismo y Libros de entierros de la parroquia de San Antonio de Toacazo, cantón Latacunga, provincia de Cotopaxi, Ecuador. 


\section{Anexo 2}

Entierros desagregados por sexo, estado civil y etnia, parroquia de San Antonio de Toacazo 1743-1857

\begin{tabular}{|c|c|c|c|c|c|c|c|c|c|c|}
\hline \multirow[b]{2}{*}{ Año } & \multicolumn{2}{|c|}{ Sexo } & \multicolumn{4}{|c|}{ Estado civil } & \multicolumn{3}{|c|}{ Etnia (1) } & \multirow[b]{2}{*}{$\begin{array}{l}\text { Total } \\
\text { anual }\end{array}$} \\
\hline & Hombres & Mujeres & Párvulo/a & Casado/a & Soltero/a & Viudo/a & Blanco/a & Mestizo/a & Indio/a & \\
\hline 1743 & 13 & 8 & 6 & 7 & 8 & 0 & 0 & 0 & 21 & 21 \\
\hline 1744 & 19 & 13 & 8 & 15 & 9 & 0 & 0 & 0 & 32 & 32 \\
\hline 1745 & 23 & 23 & 25 & 10 & 5 & 6 & 0 & 0 & 46 & 46 \\
\hline 1746 & 19 & 35 & 24 & 15 & 12 & 3 & 0 & 1 & 53 & 54 \\
\hline 1747 & 18 & 24 & 20 & 13 & 6 & 3 & 2 & 0 & 40 & 42 \\
\hline 1748 & 23 & 27 & 26 & 11 & 8 & 5 & 2 & 1 & 47 & 50 \\
\hline 1749 & 49 & 53 & 61 & 17 & 21 & 3 & 1 & 1 & 100 & 102 \\
\hline 1750 & 21 & 12 & 10 & 11 & 11 & 1 & 3 & 0 & 30 & 33 \\
\hline 1751 & 10 & 11 & 5 & 5 & 11 & 0 & 0 & 0 & 21 & 21 \\
\hline 1752 & 20 & 13 & 11 & 10 & 9 & 3 & 0 & 0 & 33 & 33 \\
\hline 1753 & 16 & 13 & 10 & 10 & 5 & 4 & 1 & 1 & 27 & 29 \\
\hline 1754 & 13 & 7 & 2 & 16 & 1 & 1 & 2 & 0 & 18 & 20 \\
\hline 1755 & 4 & 5 & 0 & 8 & 1 & 0 & 0 & 0 & 9 & 9 \\
\hline 1756 & 4 & 7 & 0 & 11 & 0 & 0 & 0 & 0 & 11 & 11 \\
\hline 1757 & 2 & 2 & 0 & 4 & 0 & 0 & 0 & 0 & 4 & 4 \\
\hline 1758 & 9 & 3 & 0 & 12 & 0 & 0 & 3 & 0 & 9 & 12 \\
\hline 1759 & 7 & 12 & 0 & 13 & 4 & 2 & 1 & 0 & 18 & 19 \\
\hline 1760 & 4 & 2 & 0 & 5 & 1 & 0 & 1 & 0 & 5 & 6 \\
\hline 1761 & 10 & 3 & 0 & 8 & 3 & 2 & 2 & 0 & 11 & 13 \\
\hline 1762 & 8 & 4 & 0 & 8 & 3 & 1 & 0 & 0 & 12 & 12 \\
\hline 1763 & 9 & 6 & 0 & 13 & 1 & 1 & 1 & 0 & 14 & 15 \\
\hline 1764 & 14 & 13 & 0 & 11 & 12 & 4 & 0 & 0 & 27 & 27 \\
\hline 1765 & 25 & 40 & 0 & 35 & 29 & 1 & 9 & 1 & 55 & 65 \\
\hline 1766 & 35 & 65 & 0 & 44 & 33 & 23 & 6 & 0 & 94 & 100 \\
\hline 1767 & 9 & 10 & 0 & 4 & 6 & 9 & 1 & 0 & 18 & 19 \\
\hline 1768 & 13 & 9 & 0 & 10 & 7 & 5 & 2 & 0 & 20 & 22 \\
\hline 1769 & 9 & 7 & 0 & 5 & 4 & 7 & 1 & 0 & 15 & 16 \\
\hline 1770 & 3 & 5 & 0 & 3 & 5 & 0 & 0 & 0 & 8 & 8 \\
\hline 1771 & 1 & 4 & 0 & 1 & 4 & 0 & 1 & 0 & 4 & 5 \\
\hline 1772 & 8 & 9 & 0 & 2 & 11 & 4 & 2 & 0 & 15 & 17 \\
\hline 1773 & 3 & 6 & 0 & 2 & 6 & 1 & 0 & 0 & 9 & 9 \\
\hline 1774 & 4 & 9 & 0 & 4 & 3 & 6 & 0 & 1 & 12 & 13 \\
\hline 1775 & 4 & 5 & 1 & 2 & 3 & 3 & 0 & 0 & 9 & 9 \\
\hline 1776 & 5 & 5 & 0 & 5 & 5 & 0 & 0 & 0 & 10 & 10 \\
\hline 1777 & 1 & 4 & 0 & 0 & 0 & 5 & 0 & 0 & 5 & 5 \\
\hline 1778 & 5 & 9 & 0 & 6 & 2 & 6 & 1 & 1 & 12 & 14 \\
\hline 1779 & 10 & 3 & 0 & 2 & 9 & 2 & 2 & 0 & 11 & 13 \\
\hline 1780 & 5 & 3 & 0 & 3 & 5 & 0 & 0 & 0 & 8 & 8 \\
\hline 1781 & 7 & 3 & 0 & 7 & 2 & 1 & 1 & 0 & 9 & 10 \\
\hline 1782 & 4 & 6 & 0 & 6 & 3 & 1 & 2 & 0 & 8 & 10 \\
\hline 1783 & 10 & 8 & 0 & 14 & 0 & 4 & 0 & 0 & 18 & 18 \\
\hline 1784 & 18 & 8 & 0 & 18 & 1 & 7 & 0 & 1 & 25 & 26 \\
\hline 1785 & 13 & 12 & 0 & 10 & 6 & 9 & 1 & 0 & 24 & 25 \\
\hline 1786 & 8 & 6 & 0 & 9 & 4 & 1 & 0 & 0 & 14 & 14 \\
\hline 1787 & 6 & 2 & 0 & 4 & 2 & 2 & 0 & 1 & 7 & 8 \\
\hline 1788 & 5 & 10 & 0 & 5 & 9 & 1 & 1 & 1 & 13 & 15 \\
\hline 1789 & 6 & 9 & 0 & 8 & 5 & 2 & 0 & 1 & 14 & 15 \\
\hline 1790 & 8 & 1 & 0 & 3 & 6 & 0 & 3 & 0 & 6 & 9 \\
\hline 1791 & 7 & 4 & 0 & 1 & 10 & 0 & 0 & 0 & 11 & 11 \\
\hline
\end{tabular}




\begin{tabular}{|c|c|c|c|c|c|c|c|c|c|c|}
\hline \multirow[b]{2}{*}{ Año } & \multicolumn{2}{|c|}{ Sexo } & \multicolumn{4}{|c|}{ Estado civil } & \multicolumn{3}{|c|}{ Etnia (1) } & \multirow{2}{*}{$\begin{array}{l}\text { Total } \\
\text { anual }\end{array}$} \\
\hline & Hombres & Mujeres & Párvulo/a & Casado/a & Soltero/a & Viudo/a & Blanco/a & Mestizo/a & Indio/a & \\
\hline 1792 & 8 & 5 & 0 & 12 & 0 & 1 & 0 & 0 & 13 & 13 \\
\hline 1793 & 12 & 1 & 0 & 11 & 0 & 2 & 1 & 0 & 12 & 13 \\
\hline 1794 & 7 & 7 & 0 & 9 & 0 & 5 & 1 & 0 & 13 & 14 \\
\hline 1795 & 6 & 9 & 0 & 12 & 0 & 3 & 0 & 0 & 15 & 15 \\
\hline 1796 & 14 & 11 & 0 & 16 & 2 & 7 & 0 & 0 & 25 & 25 \\
\hline 1797 & 15 & 6 & 3 & 7 & 7 & 4 & 1 & 0 & 20 & 21 \\
\hline 1798 & 16 & 18 & 9 & 15 & 4 & 6 & 0 & 1 & 33 & 34 \\
\hline 1799 & 7 & 14 & 9 & 6 & 3 & 3 & 2 & 0 & 19 & 21 \\
\hline 1800 & 13 & 25 & 19 & 15 & 3 & 1 & 1 & 0 & 37 & 38 \\
\hline 1801 & 21 & 17 & 27 & 6 & 4 & 1 & 2 & 0 & 36 & 38 \\
\hline 1802 & 25 & 26 & 21 & 5 & 22 & 3 & 3 & 1 & 47 & 51 \\
\hline 1803 & 14 & 8 & 0 & 13 & 5 & 4 & 1 & 1 & 20 & 22 \\
\hline 1804 & 7 & 9 & 0 & 9 & 3 & 4 & 0 & 1 & 15 & 16 \\
\hline 1805 & 6 & 2 & 0 & 2 & 3 & 3 & 0 & 0 & 8 & 8 \\
\hline 1806 & 3 & 1 & 0 & 4 & 0 & 0 & 0 & 0 & 4 & 4 \\
\hline 1807 & 9 & 2 & 0 & 8 & 3 & 0 & 0 & 1 & 10 & 11 \\
\hline 1808 & 9 & 11 & 10 & 6 & 1 & 3 & 0 & 0 & 20 & 20 \\
\hline 1809 & 11 & 12 & 2 & 18 & 2 & 1 & 2 & 0 & 21 & 23 \\
\hline 1810 & 6 & 2 & 0 & 5 & 3 & 0 & 0 & 0 & 8 & 8 \\
\hline 1811 & 3 & 0 & 0 & 2 & 0 & 1 & 0 & 0 & 3 & 3 \\
\hline 1812 & 0 & 3 & 0 & 3 & 0 & 0 & 0 & 0 & 3 & 3 \\
\hline 1813 & 2 & 3 & 0 & 4 & 1 & 0 & 0 & 0 & 5 & 5 \\
\hline 1814 & 8 & 4 & 0 & 12 & 0 & 0 & 0 & 0 & 12 & 12 \\
\hline 1815 & 4 & 3 & 0 & 6 & 1 & 0 & 1 & 0 & 6 & 7 \\
\hline 1816 & 4 & 3 & 0 & 6 & 1 & 0 & 0 & 0 & 7 & 7 \\
\hline 1817 & 3 & 5 & 0 & 8 & 0 & 0 & 0 & 1 & 7 & 8 \\
\hline 1818 & 6 & 1 & 0 & 6 & 1 & 0 & 0 & 0 & 7 & 7 \\
\hline 1819 & 7 & 4 & 0 & 10 & 1 & 0 & 0 & 0 & 11 & 11 \\
\hline 1820 & 6 & 3 & 0 & 6 & 2 & 1 & 0 & 0 & 9 & 9 \\
\hline 1821 & 6 & 8 & 0 & 13 & 1 & 0 & 0 & 0 & 14 & 14 \\
\hline 1822 & 9 & 2 & 0 & 10 & 1 & 0 & 0 & 1 & 10 & 11 \\
\hline 1823 & 11 & 7 & 0 & 12 & 3 & 3 & 2 & 0 & 16 & 18 \\
\hline 1824 & 9 & 7 & 0 & 10 & 3 & 3 & 0 & 0 & 16 & 16 \\
\hline 1825 & 84 & 57 & 95 & 14 & 30 & 2 & 5 & 2 & 134 & 141 \\
\hline 1826 & 30 & 20 & 33 & 6 & 11 & 0 & 2 & 1 & 47 & 50 \\
\hline 1827 & 23 & 26 & 31 & 9 & 5 & 4 & 3 & 1 & 45 & 49 \\
\hline 1828 & 34 & 25 & 33 & 11 & 10 & 5 & 5 & 0 & 54 & 59 \\
\hline 1829 & 24 & 40 & 34 & 12 & 11 & 7 & 2 & 3 & 57 & 64 \\
\hline 1830 & 30 & 30 & 41 & 10 & 6 & 3 & 6 & 0 & 54 & 60 \\
\hline 1831 & 60 & 54 & 82 & 15 & 9 & 8 & 8 & 1 & 105 & 114 \\
\hline 1832 & 64 & 50 & 70 & 30 & 10 & 4 & 7 & 0 & 107 & 114 \\
\hline 1833 & 41 & 35 & 39 & 19 & 13 & 5 & 9 & 0 & 67 & 76 \\
\hline 1834 & 29 & 35 & 36 & 17 & 6 & 5 & 4 & 1 & 59 & 64 \\
\hline 1835 & 41 & 22 & 30 & 16 & 10 & 7 & 7 & 0 & 56 & 63 \\
\hline 1836 & 31 & 35 & 36 & 20 & 6 & 4 & 3 & 0 & 63 & 66 \\
\hline 1837 & 48 & 38 & 45 & 25 & 11 & 5 & 10 & 0 & 76 & 86 \\
\hline 1838 & 38 & 68 & 57 & 22 & 10 & 17 & 6 & 0 & 100 & 106 \\
\hline 1839 & 72 & 66 & 91 & 10 & 29 & 8 & 11 & 1 & 125 & 138 \\
\hline 1840 & 43 & 60 & 57 & 18 & 19 & 9 & 5 & 5 & 93 & 103 \\
\hline 1841 & 30 & 31 & 33 & 14 & 9 & 5 & 5 & 2 & 54 & 61 \\
\hline 1842 & 32 & 36 & 36 & 16 & 10 & 6 & 3 & 0 & 65 & 68 \\
\hline 1843 & 29 & 31 & 25 & 18 & 7 & 10 & 5 & 0 & 55 & 60 \\
\hline 1844 & 36 & 34 & 35 & 17 & 11 & 7 & 5 & 1 & 64 & 70 \\
\hline
\end{tabular}




\begin{tabular}{|c|c|c|c|c|c|c|c|c|c|c|}
\hline \multirow[b]{2}{*}{ Año } & \multicolumn{2}{|c|}{ Sexo } & \multicolumn{4}{|c|}{ Estado civil } & \multicolumn{3}{|c|}{ Etnia (1) } & \multirow[b]{2}{*}{$\begin{array}{l}\text { Total } \\
\text { anual }\end{array}$} \\
\hline & Hombres & Mujeres & Párvulo/a & Casado/a & Soltero/a & Viudo/a & Blanco/a & Mestizo/a & Indio/a & \\
\hline 1845 & 33 & 26 & 33 & 18 & 5 & 3 & 14 & 0 & 45 & 59 \\
\hline 1846 & 49 & 36 & 46 & 20 & 11 & 8 & 15 & 1 & 69 & 85 \\
\hline 1847 & 25 & 29 & 32 & 11 & 6 & 5 & 3 & 0 & 51 & 54 \\
\hline 1848 & 34 & 35 & 29 & 24 & 7 & 9 & 9 & 0 & 60 & 69 \\
\hline 1849 & 89 & 97 & 116 & 35 & 22 & 13 & 20 & 0 & 166 & 186 \\
\hline 1850 & 27 & 35 & 24 & 21 & 10 & 7 & 5 & 4 & 53 & 62 \\
\hline 1851 & 43 & 29 & 42 & 20 & 5 & 5 & 5 & 8 & 59 & 72 \\
\hline 1852 & 31 & 16 & 18 & 15 & 5 & 9 & 2 & 3 & 42 & 47 \\
\hline 1853 & 32 & 18 & 19 & 19 & 9 & 3 & 8 & 4 & 38 & 50 \\
\hline 1854 & 31 & 19 & 13 & 20 & 9 & 8 & 4 & 4 & 42 & 50 \\
\hline 1855 & 38 & 28 & 30 & 17 & 4 & 15 & 6 & 3 & 57 & 66 \\
\hline 1856 & 46 & 29 & 39 & 11 & 10 & 15 & 9 & 4 & 62 & 75 \\
\hline 1857 & 37 & 32 & 22 & 24 & 6 & 17 & 11 & 2 & 56 & 69 \\
\hline Totales & 2168 & 2019 & 1711 & 1307 & 733 & 436 & 291 & 69 & 3824 & 4187 \\
\hline
\end{tabular}

Fuente: Libros de Entierros de la parroquia de San Antonio de Toacazo, 1743-1857.

(1) En el grupo de etnia no se han contabilizado un negro, una mulata y una zamba (ver nota de TABLA 2). 